\title{
Documentos
}

Escuela de Economía

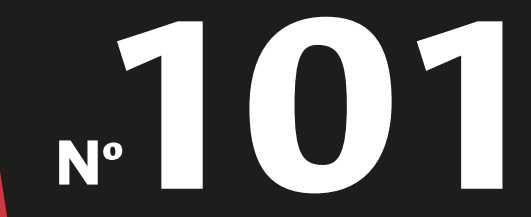

FCE - CID

\section{Crime-related Exposure to Violence and Social Preferences: Experimental Evidence from Bogotá}

Exposición a violencia relacionada con el crimen

y preferencias sociales: evidencia experimental de Bogotá

FRANCESCO BOGLIACINO

CAMILO GÓMEZ

GIANLUCA GRIMALDA

Julio de 2019

Facultad de Ciencias Económicas

Centro de Investigaciones para el Desarrollo - CID Sede Bogotá

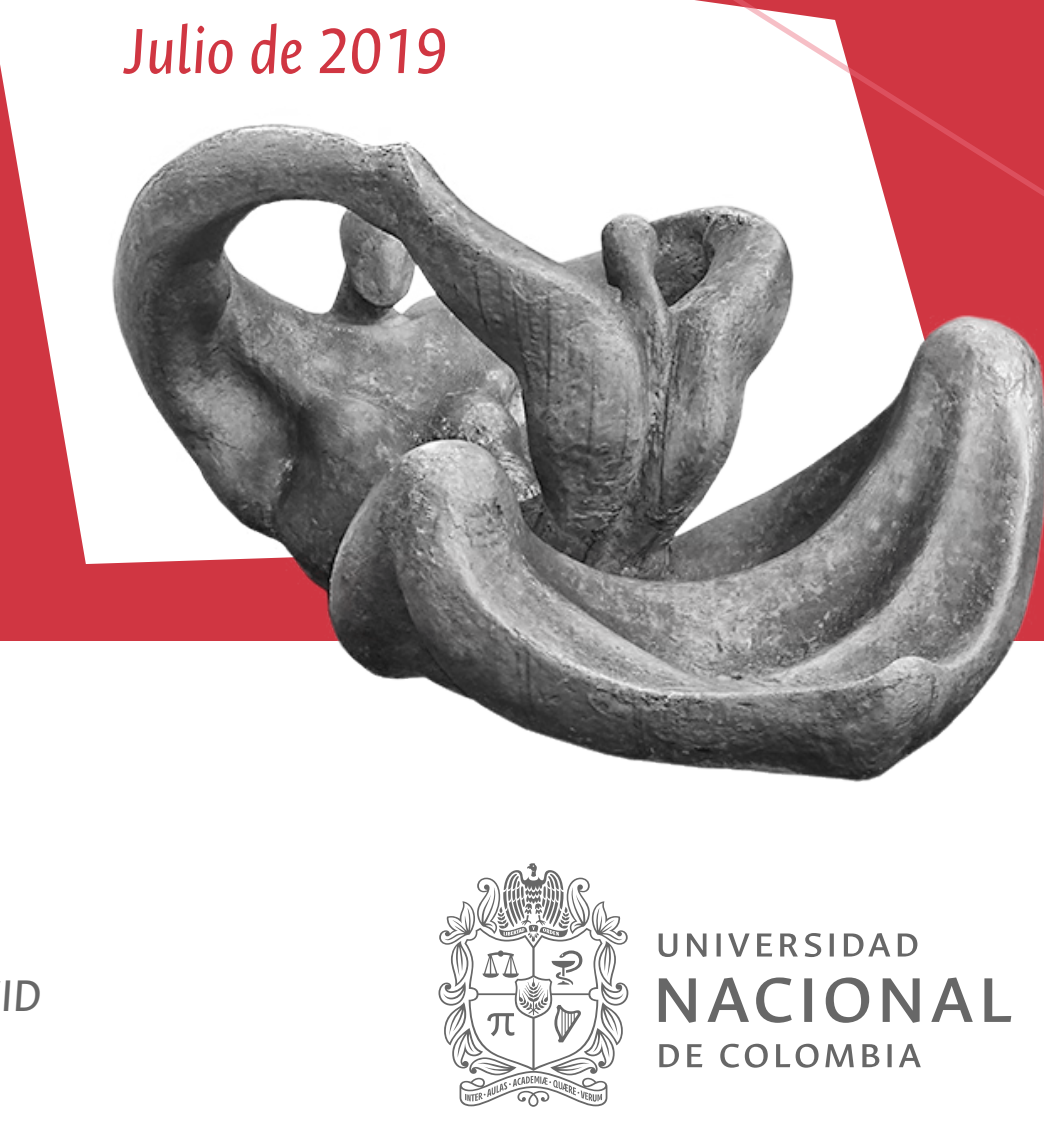


Julio 2019

\title{
CRIME-RELATED EXPOSURE TO VIOLENCE AND SOCIAL PREFERENCES: EXPERIMENTAL EVIDENCE FROM BOGOTÁ*
}

\author{
Francesco Bogliacino ${ }^{7}$, Camilo Gómez ${ }^{2}$, Gianluca Grimalda ${ }^{3}$
}

\begin{abstract}
In this paper, we study the relationship between exposure to violence (ETV) and pro-social behavior using two artefactual field experiments in Bogotá, Colombia. We focus on two dimensions of ETV: trauma and negative economic shock. In our first experiment, after manipulating a recall of ETV, we collate a number of decisions from a trust game and a dictator game. Using a design inspired by Falk and Zehnder (2013), we compare the measures of in-group bias at the district level. In our companion experiment, we use a similar design, which includes a Prisoners' Dilemma, and we introduce a 2-by-2 design where we attempt to disentangle the effect of trauma and a negative wealth shock. Our results suggest that there is a positive relationship between ETV and pro-social behavior, driven by both trauma and shock. Finally, there is evidence of in-group bias at the district level in Bogotá, but this is task specific. When we explore possible mediating variables proposed by the literature, we find that only beliefs seem to be affected, however the result is not robust. On the other hand, evidence is consistent with a generalized explanation based on either the dual system theory or the role of negative emotions.
\end{abstract}

Keywords: discrimination; trust; trustworthiness; cooperation; violence; third party punishment, social heuristics hypothesis.

JEL Classification: D63; D64; D91; C91

\footnotetext{
* Funding for these experiments come from Fundación Universitaria Konrad Lorenz (Internal Grants), and from Universidad Nacional de Colombia (Convocatoria Jesus Antonio Bejarano 2017). We thank participants to ESA World Meeting 2019, SABE sessions at WEAI 2019 in San Francisco, ESA North America 2018 in Antigua and LAWEBESS 2018 in Santiago. We also appreciate comments from participants at seminars in Universidad Nacional and CIDE. A special thanks for comments to Juan Camilo Cardenas, Maria Alejandra Vélez, John Mauro Perdomo, Zachary Grossman, Dipanwita Sarkar, William Jiménez-Leal and to all participants to BEBES. The usual disclaimer applies.

${ }^{1}$ Universidad Nacional de Colombia. Centro de Investigaciones para el Desarrollo -CID. Corresponding author: Universidad Nacional de Colombia, Carrera 30, No 45-03, Bogotá (Colombia), email: fbogliacino@unal.edu.co ${ }^{2}$ Universidad Nacional de Colombia. Centro de Investigaciones para el Desarrollo -CID

${ }^{3}$ Kiel Institute for the World Economy, Centre for Global Cooperation Research, Germany
} 


\section{EXPOSICIÓN A VIOLENCIA RELACIONADA CON EL CRIMEN Y PREFERENCIAS SOCIALES: EVIDENCIA EXPERIMENTAL DE BOGOTÁ}

\section{Resumen}

En este artículo estudiamos la relación entre exposición a violencia (ETV) y comportamiento prosocial usando dos experimentos de campo artefactuales en Bogotá (Colombia). Nos centramos en dos dimensiones de ETV: trauma y choque económico negativo.

En el primer experimento, recolectamos una serie de decisiones a partir de un juego de confianza y un juego del dictador, después de manipular un recuerdo de exposición a violencia. Usando un diseño inspirado por Falk y Zehnder (2013), recolectamos medidas de sesgo intra-grupo a nivel de localidad. En el experimento complementario usamos un diseño similar, pero incluimos un dilema del prisionero y un diseño $2 \times 2$ donde intentamos separar los efectos del trauma y de un choque negativo de riqueza.

Nuestros resultados sugieren una relación positiva entre ETV y comportamiento prosocial, guiado tanto por el trauma como por el shock. Finalmente, hay evidencia de un sesgo intragrupo a nivel de localidad en Bogotá, sin embargo, es específico a la tarea.

Cuando exploramos posibles variables mediadoras propuestas por la literatura, encontramos que solo las creencias parecen ser afectadas, pero este resultado no es robusto, mientras que la evidencia es consistente con una explicación generalizada basada en la teoría del sistema dual o en el papel de las emociones negativas.

Palabras clave: discriminación; confianza; confiabilidad; cooperación; violencia; castigo de terceros; hipótesis de la heurística social.

Clasificación JEL: D63; D64; D91; C91 


\section{DOCUMENTOS FCE-CID}

\section{ESCUELA DE ECONOMÍA}

\section{ISSN 2011-6322}

La serie Documentos FCE considera para publicación manuscritos originales de estudiantes de maestría o doctorado, de docentes y de investigadores de la Facultad de Ciencias Económicas de la Universidad Nacional de Colombia; resultado del trabajo colectivo o individual y que hayan sido propuestos, programados, producidos y evaluados en una asignatura, en un grupo de investigación o en otra instancia académica.

La serie Documentos FCE-CID puede ser consultada en el portal virtual: www.http://fce.unal.edu.co/centro-editorial/documentos.html

Rector

Dolly Montoya Castaño

\section{Vicerector General}

Pablo Enrique Abril Contreras

\section{FACULTAD DE CIENCIAS ECONÓMICAS}

\section{Decano}

Jorge Armando Rodríguez

\section{Vicedecano}

Germán Enrique Nova Caldas

\section{ESCUELA DE ECONOMÍA}

\section{Directora}

Marta Juanita Villaveces Niño

Coordinador Programa Curricular de Economía Raúl Alberto Chamorro Narváez

CENTRO DE INVESTIGACIONES PARA EL DESARROLLO CID

\section{Director}

Francesco Bogliacino

\section{Subdirectora}

Vilma Narváez
Director Centro Editorial-FCE Álvaro Zerda Sarmiento

\section{Equipo Centro Editorial-FCE} Nadeyda Suárez Morales Endir Nazry Roa Basto Yuly Rocío Orjuela Rozo

\section{Centro Editorial FCE-CID} publicac_fcebog@unal.edu.co 


\section{Introduction}

In 2000, Granada (a small village in Antioquia, Colombia) woke up under attack from the FARC-EP guerrilla group, causing the destruction of 250 buildings, and the death of 23 people from amongst both the police and civilians. Ten months later, in solidarity, the community marched together in the name of reconstruction and to contribute to the rebuilding of the village.

Comparable anecdotes have been documented from conflicts in other developing countries, demonstrating that victims of violence often choose to engage in pro-social behavior in order to contribute to the increased future welfare of other persons.

This paper aims to identify the relationship between violence and social preferences, providing an explanation for such accounts.

Violence is defined as the use of rough physical force, action or treatment to hurt or kill another. It is a common feature of human society, from the lowest level of complexity (Kelly, 2005). It has been studied extensively, as violence is associated with poorer outcomes in terms of mental and physical health. Conversely, violence has also been considered as a vector of change within human society, since state building has gone hand-in-hand with the management of war (Cohen, 1984), and the level of inequality in human societies has been leveled off through the action of violence (Scheidel, 2017).

Another defining feature of human society is large scale cooperation. Although this behavior can be documented in animals (for example, in bees and ants), and in activities such as hunting (as seen with wolves and other predators), in the former case there is closer genetic proximity, and in the latter, it is not as systematic as occurs in Homo Sapiens (Fehr and Fischbacher, 2004a). Cooperation is a constituent part of social preferences. Social preference is an umbrella concept that includes showing other-regarding concerns, for example, altruism and reciprocity in distributive choices, following social norms, participating in the community, and partaking in cooperative behavior in social interactions (Bowles and Polanía-Reyes, 2012). Trusting, cooperating and helping the community are more widespread in wellfunctioning societies (Knack and Keefer, 1997; Zak and Knack, 2001). 
Julio 2019

What do we know about the relationship between violence and social preferences? The literature shows that when ETV is war-related, the relationship is positive. A meta-review of Bauer et al. (2016), using 21 different studies, shows that people exposed to violence are more willing to engage in voting and civic participation, and have a greater respect for social norms. Although causal interpretation is always under suspicion with a variable that cannot be directly manipulated, there is consensus in the literature, and the relationship is robust to control for a vast array of observables, the use of instrumental variables and sensitivity analysis. It appears that this pro-sociality is parochial; that is, it is biased towards members of one's own group, although for this specific result, the evidence does not always point in the same direction.

Nevertheless, although war is not a memory from time long passed, as societies have become increasingly urbanized, most victims of violence are now as a result of crime. Whether or not we should expect the same kind of consequences from crime and war-related exposure to violence (ETV) is an open question. Bogliacino et al. (2017) show that the cognitive response to ETV is the same, whether victims live in the urban environment of Bogotá and are exposed to micro-criminality or when victims are internally displaced persons (IDPs) who have witnessed massacres due to internal conflicts within Colombia. In terms of pro-social behavior, there are contributions within the literature that document a positive relationship (Bateson, 2012; Dorff, 2017; Rojo-Mendoza, 2014; Kochel, 2016), however the evidence is mixed. In addition, there are papers in which a negative or non-significant relationship is claimed, but the evidence is less robust because it lacks an identification strategy (McMahon et al., 2013; Littman et al., 2019). One key difference between crime and war-related ETV is the fact that the group dimension is salient in conflict ("One for all"), where victims are usually targeted as members of a group (Sumner, 1906; Hardin, 1995), while victimization is mostly (although not necessarily) individualized when ETV is crime related.

In order for an empirical relationship to make sense, we need to posit a theoretical channel. ${ }^{4}$ Bauer et al. (2016) propose three explanations. In a standard neoclassical framework of

\footnotetext{
${ }^{4}$ Needless to say, one could also argue that the relationship is not causal, but due to selection; for example, less pro-social individuals are more likely to migrate, or reverse causation through active involvement in groups such
} 
preferences, beliefs and constraints, one could argue that the reduced opportunities to invest in physical and human capital rationally induce people to believe that they should divert their investment towards social capital, making it the equilibrium response. Alternatively, evolutionary models suggest that under group competition, parochial norms are more likely to promote survival, increasing their fitness; that is, making it more likely to be transmitted through social learning or intergenerational transmission. In some versions of these models, called gene-culture co-evolutionary models, all pro-social norms are more likely to be shared. Finally, they include an explanation from psychology, according to which survivors of a conflict rapidly recover and are more positive towards the future, becoming more likely to engage in communitarian activities. The evidence for this explanation is less compelling, because it relies on case studies, and we have also found contradicting papers, such as Moya and Carter (2019) which show that ETV increases hopelessness. Vélez et al. (2016) propose an alternative channel based on the perception of insecurity. Their result is based on Structural Equation Modelling, whereas other interpret this channel as a change in belief (Roman, 2008).

From a theoretical point of view, we make two claims. First, ETV has two dimensions. From a psychological point of view, violence is a trauma. From an economic point of view, violence induces a negative economic shock. Both are constituents of the relationship between ETV and pro-social behavior. Trauma has to do with the protracted effect of a negative event that continuously comes to mind, and we know from the literature on Post Traumatic Stress Disorder (PTSD) that it is associated with an emotional shock, where the dominant emotions are fear and anxiety (Pieschacón Fonrodona, 2011). Trauma is a multidimensional stressor; that is, the victim is incapable of coping with contextual stimuli that exceed his/her regulatory capacity (Haushofer and Fehr, 2014). It is multidimensional in the sense that victims feel a violation of the self, a loss of a sense of safety, a feeling of unfairness, and a perception of their own deviance (Frieze et al., 1987). Negative economic shocks occur in both crime-related ETV, for example, when a personal item is stolen or a serious injury is induced, and in war-related ETV, when, for example, IDPs are forced to abandon their land, or

as gangs or where trusting individuals are victimized, for example (Katz et al., 2011). However, this last statement may conflict with the evidence from the social capital literature (Takagi, Ikeda \& Kawachi, 2012). 
Julio 2019

to move from the countryside to the city, and as a result devaluing their human capital (Ibáñez and Moya, 2010). Trauma seems to induce (parochial) pro-social behavior, while the effects of negative income and wealth shock are unclear. In particular, we know from quasiexperimental studies that negative income shocks induce more anti-social behavior, such as property crimes (Bignon, Caroli, \& Galbiati, 2017; Cortés, Santamaría \& Vargas, 2016; Dube and Vargas, 2013). However, naturally occurring situations make inequality due to random shocks salient, potentially inducing lower pro-social behavior. In fact, we know from a controlled experiment by Bejarano et al. (2018) that in an investment game (Berg et al., 1995) with shock-induced inequality, there is less trust by senders. On the other hand, economic shock occurring as a result of ETV focuses attention on the author rather than the environment, making victims more collaborative with no perpetrators.

Second, we argue that psychology and neuroeconomics provide generalized explanations of the nexus between ETV and pro-social behavior. In fact, a positive outcome is consistent with the Social Heuristics Hypothesis (Rand et al., 2012), since both trauma and negative economic shocks act as a cognitive load, making intuition prevalent. Moreover, emotional reactions associated with both channels activate the amygdala (Ledoux, 2002), the region of the brain responsible for social cognition (Adolphs, 2010), and is more likely to make treated individuals prone to recognize trustworthy signals in the controlled environment or in their own community, thus favoring cooperation (Declerk and Boone, 2015). From a neuroeconomic point of view, it is also easier to explain heterogeneous results in an urban environment, where other cues are more salient, or where intuition provides less guidance (see the debate in Kvarven et al., 2019, Rand, 2019, Alós-Ferrer and Garagnani, 2018, Krajbich et al., 2015).

In this paper, we provide evidence from two controlled experiments in Bogotá, Colombia. From our first experiment, we collate a number of decisions in strategic environments where an individual's well-being is salient. We also compare a set of other dependent variables related to beliefs, social norms, aspirations, and a perception of insecurity, which allow testing of whether or not the mediating variables proposed in Bauer et al. (2016) and Vélez et al. (2016) hold for a crime-related ETV environment. Group belonging is less salient in an 
urban environment, where we cannot easily use the community to discriminate between locals and outsiders. However, we build upon Falk and Zehnder, who identify in-group bias at the district level. Using a similar design, we collect district contingent decisions.

In our companion experiment, we build upon the previous one, but we use a different experimental task, and we introduce a 2-by-2 design where we try to disentangle the effect of trauma and a negative wealth shock.

According to the Harrison and List's (2004) taxonomy, our subject pool is nonstandard, and our experiments can be labelled as artefactual field experiments.

In this paper, the empirical strategy is based on both exogenous manipulation and control for selection. By measuring ETV through a questionnaire, we can split the sample according to the participants' degree of exposure. Since ETV is self-reported, we use controls at the level of the individual and of the district of residence in order to have meaningful comparisons. We then manipulate trauma and shock using random assignment. For the first, we use priming; a psychological tool (usually a question) to induce a certain emotional state, inspired by the research on the victims of 9/11 (Lerner et al., 2003, see also Callen et al., 2014). The advantage of a question is that it can be randomly assigned (alternated with a control question). In particular, we use either a Violence Recall (VR) or a Neutral Recall (NR), which are, respectively, a question asked in order to recall a fearful or anxious experience, and the recall of a general experience not emotionally framed. In order to manipulate shock, we use a random negative loss of endowment.

Our results suggest that there is a positive relationship between ETV and pro-social behavior. When we explore possible mediating variables proposed by the literature, we find that only beliefs seem to be affected (however, the evidence is mixed), whereas this is consistent with a neuroeconomics explanation. Finally, there is evidence of in-group bias at the district level in Bogotá, but this bias is task specific.

We proceed as follows. Section II presents the first experiment; Section III the second experiment; Section IV discuss mechanisms, and Section V concludes. Supplementary Online 
Julio 2019

Materials (SOM) include all of the procedures, supporting analysis and additional material and is available from the authors upon request.

\section{Experiment I}

\subsection{Experimental Design}

We run our first experiment in Bogota. Although currently less violent than in its past, the capital of Colombia is still a dangerous place to live in comparative terms and provides a significant variation in terms of exposure to violence across its territory. Administratively, it is divided into 20 districts; one of which is completely rural. Districts are large administrative units, subdivided in neighborhoods. A map of the districts is in SOM Figure A3 - 1.

We recruit participants aged 18-24 from all of the urban districts. We restrict age to this range because it reduces the likelihood of self-selection into a neighborhood.

The stage game is a version of the investment game by Berg et al. (1995) and proceeded as follows (see Figure 1 below): The trustor and the trustee are endowed with two tokens and interact in a sequential game. Each token is worth 4,000 Colombian pesos (COP, around USD 2.00 at the time). We name them sender and receiver in the instructions as we choose a neutral framing. In the first stage, the trustor moves first and can send either zero, one or two tokens to the trustee. The amount sent is tripled by the experimenter. The trustee's choices (trustworthiness) are collected through the strategy method (Selten, 1967). For each possible amount sent by the trustor (one or two tokens), the trustee can decide whether or not to send it back. If the trustee sends back, then the two parties end up with an equal number of tokens (three each in the first case and four each in the second case).

Each party takes a turn as trustor and trustee, and one of the two choices is paid, randomly chosen at the end of the game. The matching is perfect stranger; that is, no one interacts with the same person twice.

While acting as a sender, the participant makes contingent decisions on the (urban) district of the receiver (i.e., a total of 19 decisions). 
We have a 2-by-2 design. One treatment is the Violence Recall versus the Neutral Recall. In the former, participants are asked to recall a violent, fearful or anxious experience that occurred during last year, whereas in the latter we ask for any experience that has occurred. The other treatment is the presence of a third-party punishment (TPP). Randomization occurs at the session level. In Table 1, we summarize the design, with sessions and participants per condition.

The Violence/Neutral Recall occurs just prior to making the first decision, and after explaining the stage game. It is read aloud, and participants have five minutes to complete a paper sheet with answers. The questions are the following:

- We are interested in understanding your daily experiences. Could you describe an event from the past year?

- We are interested in understanding your daily experiences that may make you fearful or anxious. This could be anything; for example getting sick, experiencing violence, losing a job, etc. Could you describe one event in the past year that caused you fear or anxiety?

In the TPP sections, we recruit 50\% more participants and randomly assign one third of them to another room to play the third-party role. The third party is named supervisor. He/she decides how much to spend of his/her endowment to reduce the endowment of the receiver in the trust game, conditional on the choice made. The punishment has a multiplier of five. Through the strategy method, we collect four choices of the supervisor: if he/she decides to punish when the receiver decides to split tokens equally, we label it anti-social punishment, while in the other two cases (when the receiver keeps all the tokens), we have a measure of altruistic punishment. The supervisor receives an endowment equal to half the surplus of the transaction between the trustor and the trustee (three tokens in the case of transfer of half the endowment and four tokens in the case of transfer of two tokens). For the supervisor, the amount is in COP, and he/she can spend zero or any multiple of $100 \mathrm{COP}$, up to the maximum amount that would leave the receiver with zero endowment.

We collect a set of beliefs for all participants. 
Julio 2019

After finishing this stage, everybody is asked to participate in a dictator game with NGOs as recipients.

Figure 1. The stage game

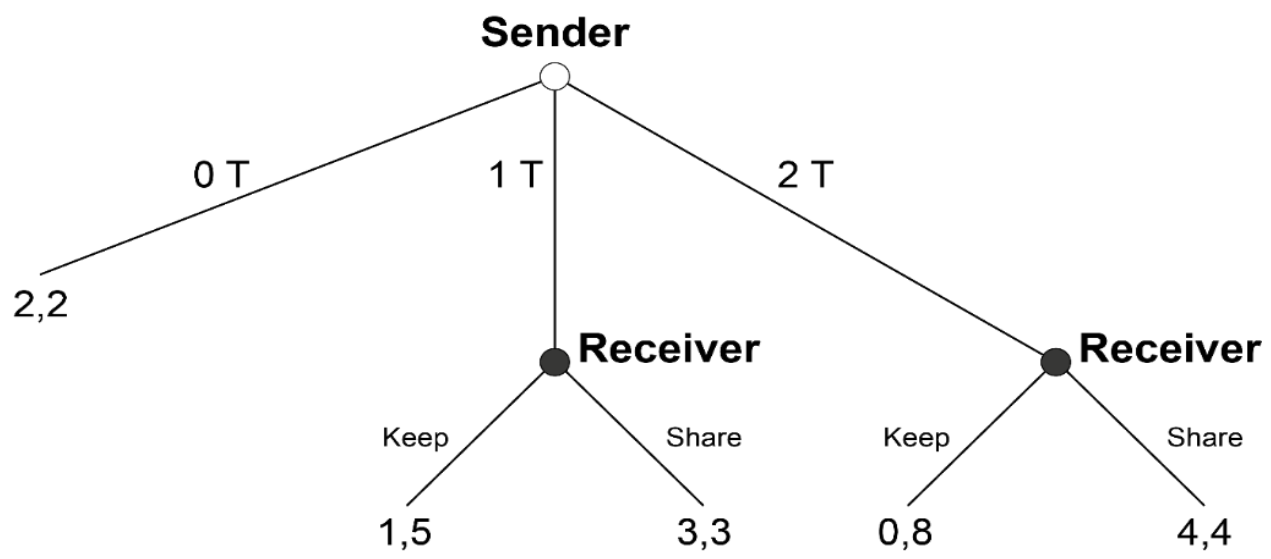

Table 1. Experimental conditions and sample: Experiment 1

\begin{tabular}{ccc}
\hline & Violence Recall & Neutral Recall \\
\hline \multirow{2}{*}{ TPP } & TPP and Recall & Only TPP \\
& $\mathrm{N}=92$ & $\mathrm{~N}=125$ \\
No TPP & Only Recall & Control \\
& $\mathrm{N}=30$ & $\mathrm{~N}=34$ \\
\hline
\end{tabular}

\subsection{The experimental procedures}

Experimental sessions were conducted in the Fundación Universitaria Konrad Lorenz in Bogotá, from August 2013 to September 2013. The instructions for the stage games are similar to Bogliacino, Jiménez and Grimalda (2018). The average session had either 30 participants (with TPP) or 20 (without TPP).

At the beginning of each session, participants received a randomly assigned ID number that was printed on an envelope. When privately distributing the envelopes, information on the district of residence of the participants was collected and, was entered in the matching algorithm. For those sessions without TPP, half even and half odd numbers were handed out. For those with TPP, we took care that one third of the participants received an odd number, one third an even number, and one third a special set of numbers (larger than the other ones). 
Odd and even numbered participants were seated in one room, where the principal investigator led the session. Those who received the special numbers were seated in a separate room, where another experimenter was reading the instructions.

All instructions were read aloud and illustrated on a whiteboard. All decisions were collected using paper and pencils. In each room, cardboard separators were used to ensure that decisions were collected anonymously (a picture from the first experiment is in Photo A4 - 1 of the SOM). Visual representations of the interactions were also distributed.

It was explained to participants that their payment would be the result of two out of three decisions, and that one between the first two decisions would be randomly drawn at the end. The draw was performed by a volunteer.

We checked for comprehension through two sets of questions. After collecting the answers to the first set of questions, the experimenter illustrated the cases on the whiteboard and explained the correct answers. At the end of the first comprehension check, a set of five multiple answers questions was administered, the exactness of which were checked individually, and the number of errors recorded.

After this phase and before assigning the role of sender and receiver, the Violence Recall or Neutral Recall was read aloud, and the participants had five minutes to write an answer. A random draw was carried out assigning people either holding an odd ID number or an even ID number the sender role. The other group was assigned the receiver role. Both senders and receivers were asked to submit their decision regarding the stage game on a decision sheet. The sender had to decide how much he/she was willing to send to a participant conditional on the district of residence. Receivers' decisions were collected through the strategy method, answering whether they wanted to keep all or half of the tokens, conditional on the sender transferring one or two tokens. When the choices were made, the decision sheets were collected.

Subjects were then told that the second decision consisted of another trust game, where roles would be swapped. Those who acted as receivers (senders) in the first decision acted as senders (receivers) in the second decision. New pairs were formed. 
Julio 2019

In the supervisor session, after following the same steps as in the principal session up to the Violence/Neutral Recall question, the participants were asked how much they would like to spend to reduce the payoff of the receiver, for each possible case.

After the trust game, sender, receiver and supervisor were all required to declare their beliefs. The sender was asked to predict the behavior of the receiver, and the behavior of the supervisor in the cases of free riding from the counterpart. The receiver was asked to predict the decision by the sender. We did not ask participants to predict each possible scenario because of time limitations. In the sessions without TPP, no question related to the supervisor was asked. The supervisor was asked to predict the behavior of the sender and receiver. Each question was incentive compatible, but the amount paid was small (250 COP). Given the heterogeneous level of education within our sample and the complicated nature of quadratic scoring rules, we considered a belief correct up to a margin of 400 COP. The use of small payment reduced the saliency of the decisions to minimize the likelihood of hedging by participants (Blanco, et al., 2010).

After the beliefs were collected, the last decision was a dictator game with 4,000 COP that consisted of sending zero, or any multiple of 400 COP, to one of three NGOs (Eckel and Grossman, 1996).

While a questionnaire was handed out, the decisions were matched, the payments calculated, and then envelopes containing money were distributed upon completion of the questionnaire. An English version of all the materials and instructions are included in the SOM.

In total, we conducted nine sessions, with 281 participants. The participants received on average COP 16,000 (with 7,050 sd). The sessions lasted two hours with very little variation.

\subsection{Identification strategy}

We run the following estimation:

$y_{i j}=\alpha+\beta_{0} V R_{i j}+\beta_{1} H E T V_{i j}+\beta_{2} V R_{i j} \cdot H E T V_{i j}+X_{i j} \gamma+Z_{j} \delta+\varepsilon_{i}$ 
where $i$ indicates participant, and $j$ the district. $Y$ is our dependent variable, VR is the dummy for the Violence Recall versus neutral question, HETV is the dummy for those highly exposed to violence, $X$ is a set of individual level controls (including the dummy for TPP), $Z$ is a set of district level controls, and epsilon are individual level unobservables.

Individual level controls are mostly income and education-related: besides age and gender, we use both the Socio-Economic Strata of the household dwelling, ${ }^{5}$ an indicator for Body Mass Index, computed from self-reported height and weight in the post experimental questionnaire, and the father's educational level, again self-reported in the questionnaire.

We use a battery of district-level controls from the Bogotá Household Survey (Encuesta Multiproposito de Bogotá, EMB 2014) to control for this issue. In particular, we use the following variables: income, education, heterogeneity, mobility, displacement rate and home ownership. Income corresponds to average income per capita in the district; 'Education' corresponds to the share of people aged 18-25 who study; 'Heterogeneity' is the percentage of SES 1 and 2 households; 'displacement rate' is the rate of Internally Displaced Population as a share of the population of the district, 'Mobility' is the number of households in that district that moved to another location in the last 3 years; 'Home ownership' is selfexplanatory. These are the equivalent to the variables used in Falk and Zehnder (2013), adapted to Colombia.

HETV is a dummy based on self-reported ETV. We recover these data from the postexperimental questionnaire. In particular, we use the following questions:

- Have you been subjected to a physical assault in the last twelve months?

- Have any of your family members been subjected to a physical assault in the last twelve months?

\footnotetext{
${ }^{5}$ In Colombia each dwelling is assigned one of six tax tiers, depending on the market value and other characteristics of the dwelling, as well as the area in which the dwelling is located. There exist six tax tier levels, with 1 (6) indicating the lowest (highest) tax tier, and thus lowest (highest) Socio-Economic Status. Utility bills are differentiated per tier, being ceteris paribus higher for dwellings estimated as having higher market value. People do not expect to be stigmatized according to SES, which ensures the truthfulness of this construct as a measure of socio-economic status (Bogliacino, Jiménez and Reyes, 2018).
} 
Julio 2019

- Have you found yourself in the middle of a confrontation involving the use of guns or other firearms in the last five years?

- Have you been subjected to direct violence in the last twelve months?

From these data, using a principal components analysis, we retain the first component ${ }^{6}$ and compute a composite index of ETV. The median level of ETV is bounded away from zero, thus the coefficient should be interpreted as an intensive margin and not an extensive one.

Our coefficient of interest is $\beta_{2}$. In terms of Rubin's alternative potential outcomes model (Rubin, 1974), it is the impact on the outcome variable of recalling for those highly exposed to violence, with respect to those with lower ETV. The identification assumptions are twofold: first, the effect of the recall would have been the same for Low ETV and High ETV individuals, in absence of the increase in victimization, after controlling for observables; and second, the effect of the recall in each group can be interpreted causally since it is randomly administered. We interpret Violence Recall as the inducement of the mental and emotional state related to the ETV, thus the difference in its effect between Low and High ETV is due to trauma.

We now come to the dependent variables. From the trust game, we collect four measures. The sender decision is the level of trust, computed as the percentage of the available endowment. We calculate the average amount sent across districts and we also look at separate decisions per district. The two decisions by the receiver are our measures of trustworthiness: return upon one token sent and return upon two tokens sent, labelled Return (1T) and Return (2T). Finally, we estimate the share sent to NGOs, as a measure of altruism.

To avoid the distortion of multiple hypotheses testing, we normalize the variables in z-score (subtracting the average and dividing by the standard deviation) and run regressions clustering standard errors at the individual level.

\footnotetext{
${ }^{6} \mathrm{KMO}=0.50$, the eigenvalue of the first component is 1.28 , and the share of the variance explained is $32 \%$.
} 


\subsection{Results: Impact on Pro-social behavior}

In the SOM Tables A1 - A2, we provide descriptive statistics of the sample. We also report the mean and standard deviation of the outcome variables by TPP and by recall in SOM Table A3.

We move to the regression analysis. In Figure 2 below, we report the main result. On the $y$ axis, we report the outcome variable centered in zero and in point of standard deviation. We separate four groups. In the left half, there are those who were less exposed to violence and in the right half, those who were highly exposed. In each half, we split between those who are asked to recall a neutral experience, and those who are asked to recall a fear or anxietyinducing experience.

Figure 2. The impact of ETV on pro-social behavior

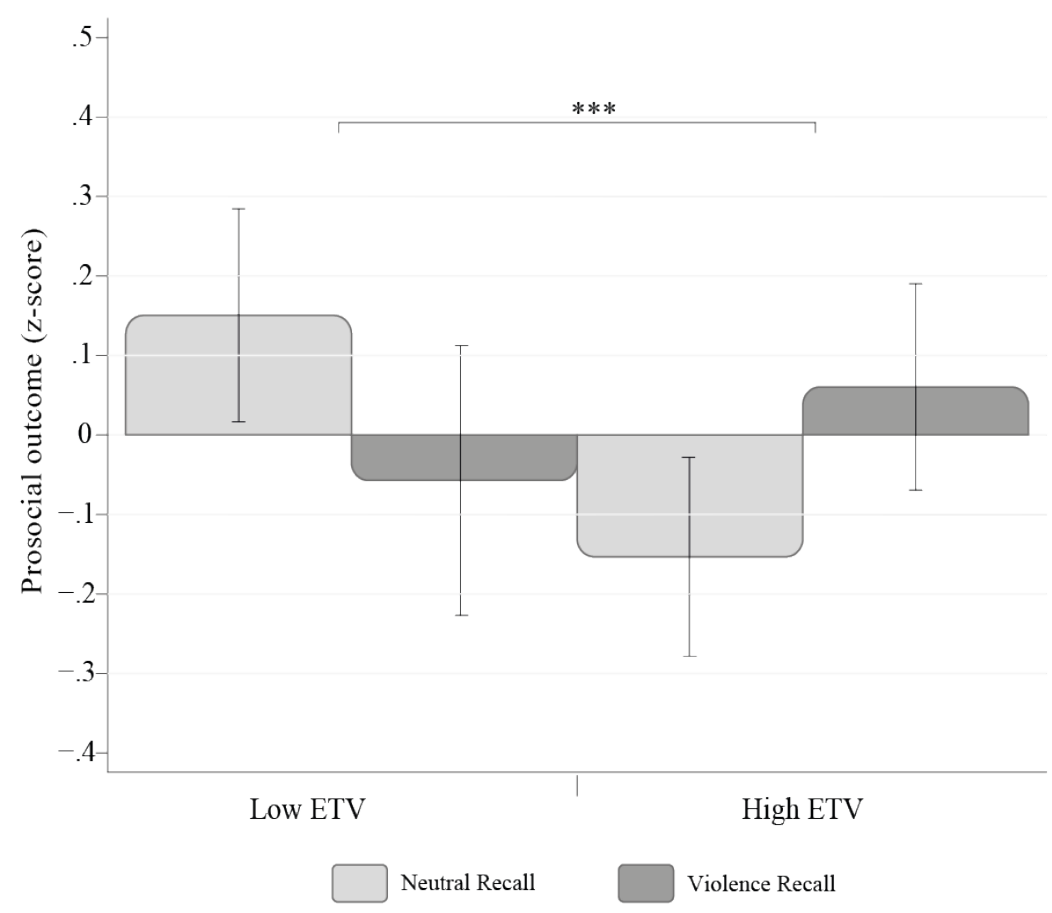

Source: Author's elaboration. The pro-social outcome (z-score of the trust, trustworthiness (1T), trustworthiness, (2T) and altruism measures) is broken down by Violence Recall condition (Violence recall vs. Neutral recall) and levels of ETV; high or low ETV. High exposure to violence identifies subjects lying above the distribution's median of the self-reported violence index. Error bars reflect $\pm 95 \%$ confidence intervals. Top horizontal bar shows the statistical significance of the difference in difference coefficient from the regression reported in Table 2. ${ }^{* * *} p<0.01,{ }^{* *} p<0.05$, $* p<0.1$. 
Julio 2019

For each group, we report the average level and the confidence interval at 95\%. Above the column, we report the results of the dif-in-dif estimation, using all the controls. As can be seen, recalling under high exposure with respect to low exposure, with respect to no recalling, has a positive and significant effect of 0.53 standard deviations $(t=2.82, p=0.005)$. This can be reconstructed as follows. Participants with low ETV become less pro-social when asked to recall a fearful event. Victims become more pro-social when they are asked to recall the event. The difference between the two is positive. The regression is reported in Table 2 below.

Table 2. Difference-in-difference estimation of the impact of self-reported ETV

\begin{tabular}{lcccc}
\multicolumn{5}{c}{ on prosocial outcome } \\
\hline \multirow{4}{*}{ VARIABLES } & $(1)$ & $(2)$ & $(3)$ & $(4)$ \\
\hline TPP & 0.01 & -0.04 & 0.06 & 0.02 \\
& $(0.08)$ & $(0.09)$ & $(0.09)$ & $(0.10)$ \\
VR & -0.21 & $-0.29^{* *}$ & $-0.25^{*}$ & $-0.30^{* * *}$ \\
& $(0.14)$ & $(0.15)$ & $(0.14)$ & $(0.14)$ \\
HETV & $-0.30^{* * *}$ & $-0.27^{* *}$ & $-0.33^{* * *}$ & $-0.28^{* *}$ \\
& $(0.11)$ & $(0.13)$ & $(0.11)$ & $(0.13)$ \\
VR \# HETV & $0.42^{* *}$ & $0.53^{* * *}$ & $0.45^{* * *}$ & $0.53^{* * *}$ \\
& $(0.17)$ & $(0.19)$ & $(0.17)$ & $(0.19)$ \\
Individual level controls & $\mathrm{NO}$ & YES & $\mathrm{NO}$ & YES \\
District level controls & $\mathrm{NO}$ & $\mathrm{NO}$ & YES & YES \\
Constant & 0.15 & $-1.23^{* *}$ & $-2.16^{*}$ & $-4.57^{* * * *}$ \\
& $(0.09)$ & $(0.62)$ & $(1.18)$ & $(1.50)$ \\
\hline Observations & 831 & 735 & 831 & 735 \\
R-squared & 0.01 & 0.04 & 0.03 & 0.06 \\
F test & 2.028 & 2.828 & 1.882 & 3.188 \\
\hline
\end{tabular}

Note: The dependent variable 'Prosocial' is the normalization in z-score of the trust, trustworthiness (1T), trustworthiness (2T) and, altruism measures. This variable is centered in zero and in point of standard deviation. Individual level controls include: age, gender, SES, TPP, Body Mass Index, and Father's education. District level controls are income, education, displacement rate, heterogeneity, mobility, and home ownership of the district where the participant lives. VR identifies participants who were asked to recall emotions of anxiety and fear connected to an experience of violence, while all others were asked to recall either emotionally-neutral or joyful experiences. HETV is a dummy for high exposure to violence, built from the post experimental questionnaire. Clustered standard errors at individual level in parentheses. ${ }^{* * *} p<0.01,{ }^{* *} p<0.05,{ }^{*} p<0.1$. (See the complete regression in Table A 4 in SOM).

There are other important comparisons that are worth making, which are reported in Table 3 below. These coefficients can be easily calculated from the output of the dif-in-dif regressions 
and significance levels calculated through a Wald test. We can see that HETV are less prosocial than LETV if we restrict the analysis to those who do not recall. HETV are more prosocial than LETV when both are asked to recall. Finally, recalling has a positive effect on HETV.

Table 3. Comparing the four groups defined by ETV and Recall

$\begin{array}{cc}\text { Variable } & \text { Prosocial (z-score) } \\ y_{i}^{H E T V, V R}-y_{i}^{H E T V, N R} & 0.20^{*} \\ y_{i}^{H E T V, V R}-y_{i}^{L E T V, V R} & (0.12) \\ y_{i}^{H E T V, V R}-y_{i}^{L E T V, N R} & 0.23 \\ y_{i}^{H E T V, N R}-y_{i}^{L E T V, V R} & (0.14) \\ y_{i}^{H E T V, N R}-y_{i}^{L E T V, N R} & -0.12 \\ y_{i}^{L E T V, V R}-y_{i}^{L E T V, N R} & 0.11) \\ {\left[\left(y_{i}^{H E T V, V R}-y_{i}^{L E T V, V R}\right)-\left(y_{i}^{H E T V, N R}-y_{i}^{L E T V, N R}\right)\right]} & 0.02 \\ \end{array}$

Note: Elaboration based on Table 2 above. Robust standard errors (clustered at the individual level for regression in the last column) are reported in parentheses. ${ }^{* * *} p<0.01,{ }^{* *} p<0.05,{ }^{*} p<0.1$.

In the SOM Tables A6-A9, we also report separate regressions for each outcome variable, the results show that there is a positive and significant impact on trust $(t=1.89, p=0.0625)$ and trustworthiness ( 1 token) $(\mathrm{t}=2.82, \mathrm{p}=0.005) .^{7}$

\subsection{Results: In-group bias}

In Table 4, we report the estimation for in-group bias. We use the 19 decisions at the district level to estimate a panel data model. We introduce a dummy equal to one when the participant is sending towards a resident in their own district and zero for the other 18 .

We add interactions with HETV and with VR to detect if there is a differential impact of ETV on in-group bias.

\footnotetext{
${ }^{7}$ When we estimate the standard errors through the Romano and Wolff (2005) procedure, to correct for multiple hypotheses testing, the result is a positive and significant impact for at least one of the measures, trustworthiness ( 1 token) $(p=0.009)$.
} 
Julio 2019

Table 4. In group bias

\begin{tabular}{lc}
\hline VARIABLES & Trust \\
\hline In-group & $0.21^{* * * *}$ \\
VR & $(0.03)$ \\
& -0.04 \\
HETV & $(0.05)$ \\
& -0.07 \\
VR \# HETV & $(0.05)$ \\
& $0.13^{*}$ \\
In-group \# VR & $(0.07)$ \\
& -0.02 \\
In-group \# HETV & $(0.07)$ \\
& -0.04 \\
In-group \# HETV \# VR & $(0.05)$ \\
& 0.03 \\
Individual level controls & $(0.09)$ \\
District level controls (sender) & YES \\
District level controls (receiver) & YES \\
Constant & YES \\
& $-1.08^{*}$ \\
\hline Observations & $(0.64)$ \\
Number of id & 3,465 \\
Individual random effects & 184 \\
\hline Varlable 'Trust' is the transfer of tokens by sender for & YES \\
\hline
\end{tabular}

Note: The dependent variable 'Trust' is the transfer of tokens by senders for each of the 19 districts. The variable is constrained between 0 and 1. 'In-group' is a dummy variable that identifies the observation when the transfer is to the same district of the participant. 'VR' identifies participants who were asked to recall emotions of anxiety and fear connected to an experience of violence, while all others were asked to recall either emotionally-neutral or joyful experiences. 'HETV' is a dummy for exposure to violence, built from an index based on post experimental questionnaire. Individual level controls are age, gender, SES, father's education and body mass index. District level controls are income, education, displacement rate, heterogeneity, mobility, and home ownership. Clustered standard errors at individual level in parentheses. $* * * p<0.01$, ** $p<0.05, * p<0.1$. (See the complete regression in Table A 10 in SOM)

As can be seen, participants sent on average $21 \%$ tokens to other participants in the same districts in excess of what they sent to those from other districts. This result is robust to different estimations. In SOM Table A10, we report fixed effects, random effects and alternative sets of controls. Notably, this result is not driven by wealthy participants. One could argue that due to the decreasing marginal utility of income, it is rational to expect more trustworthiness by rich people. Since Bogotá is largely segregated by socio-economic level, as 
are most Latin-American capitals (Bogliacino, Jiménez and Reyes, 2018), rich people are more trusting of those who live in the same neighborhood because they are of a comparable socioeconomic level. To assess this alternative explanation, we split the sample according to income status: we separate both rich and poor districts according to the average income of the district, and rich and poor participants according to their self-reported SES. Results are reported in Table 5 below. As can be seen, in-group bias is robust. However, we could not find differences according to ETV.

Table 5. In-group bias by poor and wealthy district and individual characteristics

\begin{tabular}{|c|c|c|c|c|}
\hline VARIABLES & $\begin{array}{c}\text { (1) } \\
\text { Trust } \\
\text { (poor } \\
\text { district) }\end{array}$ & $\begin{array}{c}\text { (2) } \\
\text { Trust } \\
\text { (wealthy } \\
\text { district) }\end{array}$ & $\begin{array}{c}\text { (3) } \\
\text { Trust } \\
\text { (poor } \\
\text { individual, by } \\
\text { SES) } \\
\end{array}$ & $\begin{array}{c}\text { (4) } \\
\text { Trust } \\
\text { (wealthy } \\
\text { individual, by SES) }\end{array}$ \\
\hline In-group & $\begin{array}{c}0.23^{* * * *} \\
(0.05)\end{array}$ & $\begin{array}{c}0.19 * * * * \\
(0.05)\end{array}$ & $\begin{array}{c}0.22 * * * \\
(0.05)\end{array}$ & $\begin{array}{c}0.20 * * * \\
(0.05)\end{array}$ \\
\hline Violence recall & $\begin{array}{c}0.04 \\
(0.07)\end{array}$ & $\begin{array}{l}-0.09 \\
(0.06)\end{array}$ & $\begin{array}{c}0.10 \\
(0.06)\end{array}$ & $\begin{array}{l}-0.12 * \\
(0.06)\end{array}$ \\
\hline HETV & $\begin{array}{l}-0.03 \\
(0.07)\end{array}$ & $\begin{array}{c}-0.13^{* * *} \\
(0.06)\end{array}$ & $\begin{array}{c}0.06 \\
(0.08)\end{array}$ & $\begin{array}{c}-0.15 * * * \\
(0.05)\end{array}$ \\
\hline Violence recall \# HETV & $\begin{array}{l}0.17^{*} \\
(0.10)\end{array}$ & $\begin{array}{c}0.11 \\
(0.08)\end{array}$ & $\begin{array}{c}0.04 \\
(0.10)\end{array}$ & $\begin{array}{l}0.20 * * \\
(0.08)\end{array}$ \\
\hline In-group \# Violence recall & $\begin{array}{l}-0.09 \\
(0.11)\end{array}$ & $\begin{array}{c}0.03 \\
(0.08)\end{array}$ & $\begin{array}{l}-0.13 \\
(0.10)\end{array}$ & $\begin{array}{c}0.06 \\
(0.08)\end{array}$ \\
\hline In-group \# HETV & $\begin{array}{l}-0.07 \\
(0.08)\end{array}$ & $\begin{array}{l}-0.01 \\
(0.07)\end{array}$ & $\begin{array}{l}-0.04 \\
(0.08)\end{array}$ & $\begin{array}{l}-0.03 \\
(0.07)\end{array}$ \\
\hline In-group \# HETV \# Violence recall & $\begin{array}{c}0.06 \\
(0.14) \\
0.00\end{array}$ & $\begin{array}{l}0.03 \\
(0.11) \\
0.02^{* * *}\end{array}$ & $\begin{array}{l}0.14 \\
(0.15) \\
-0.01\end{array}$ & $\begin{array}{l}-0.03 \\
(0.11) \\
0.02^{* *}\end{array}$ \\
\hline $\begin{array}{l}\text { Individual level controls } \\
\text { District level controls (sender) } \\
\text { District level controls (receiver) }\end{array}$ & $\begin{array}{l}\text { YES } \\
\text { YES } \\
\text { YES }\end{array}$ & $\begin{array}{l}\text { YES } \\
\text { YES } \\
\text { YES }\end{array}$ & $\begin{array}{l}\text { YES } \\
\text { YES } \\
\text { YES }\end{array}$ & $\begin{array}{l}\text { YES } \\
\text { YES } \\
\text { YES }\end{array}$ \\
\hline Constant & $\begin{array}{l}-0.33 \\
(0.54)\end{array}$ & $\begin{array}{l}-0.08 \\
(0.34)\end{array}$ & $\begin{array}{c}0.04 \\
(0.47)\end{array}$ & $\begin{array}{c}0.17 \\
(0.35)\end{array}$ \\
\hline Observations & 1,589 & 1,876 & 1,382 & 2,083 \\
\hline Number of id & 84 & 100 & 74 & 110 \\
\hline Individual random effects & YES & YES & YES & YES \\
\hline
\end{tabular}

Note: The dependent variable 'Trust' is the transfer of tokens by senders for each of the 19 districts. The variable is constrained between 0 and 1. 'In-group' is a dummy variable that identifies the observation when the transfer is to the same district of the participant. 'VR' identifies participants who were asked to recall emotions of anxiety and fear connected to an experience of violence, while all others were asked to recall either emotionally-neutral experiences. 'HETV' is a dummy for exposure to violence, built from an index based on post experimental questionnaire. Individual level controls are age, gender, SES, father's 
Julio 2019

education and body mass index. District level controls are district education, displacement rate, heterogeneity, mobility, and home ownership of the district where the participant lives. Clustered standard errors at individual level in parentheses. ${ }^{* * *} p<0.01,{ }^{* *} p<0.05,{ }^{*} p<0.1$. (See the complete regression in Table A 11 in SOM).

\section{Experiment 2}

\subsection{Design}

The second experiment was also conducted in Bogotá. Participants were recruited from all districts in Bogotá, excluding the rural district.

We collected data from three incentivized choices and from a questionnaire. Decision one was a Prisoner's Dilemma (PD), followed by a belief elicitation on the counterpart's decision. Decision three was a dictator game with NGOs, similar to the first experiment.

The experimental currency was called "point", the exchange rate was COP 1,000 per point. The final payment was the sum of a show-up fee (two points), the outcome of the PD, and one randomly chosen decision between the dictator and the belief. We chose to always pay the PD, because it was our main decision and it was necessary to make the NWS salient (see below). We randomly paid one of the other two decisions in order to avoid deception and possible income effects. The maximum payment assigned to belief and dictator was four points.

The PD instructions were a variation of Holt and Capra (2000), with a loss framing. Participant received an initial endowment of 20 points, and decided strategically between two options, always determining losses, as in Figure 3 below. The two strategies were associated with two colors; blue and green. We did not use charged words in order to avoid normative experimenter effects. The blue color was the cooperative strategy.

The loss framing was necessary to introduce the NWS through manipulation of the initial endowment. The evidence suggests that behavior in the PD is not sensible to the loss framing (de Heus, Hoogervorst \& Dijk, 2010). 
Figure 3. The normal form of the Prisoners' Dilemma

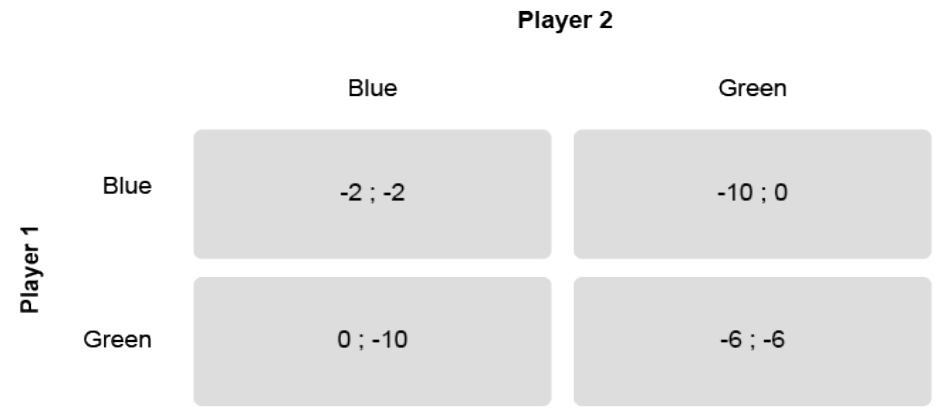

Source: Author's elaboration

The experimental questionnaire was divided into two blocks. The first block of questions was administered at the beginning of the experiment before all of the experimental tasks. This block included questions about gender, age, civil status, residence district, and socioeconomic strata (SES). It was necessary to ask this question at the beginning to avoid ex post manipulation of the residential district. The second block was asked at the end. The latter included questions about aspirations, the frequency of political participation and a set of questions to measure ETV and perception of insecurity (following the questionnaire format of Vélez et al., 2016).

We have a 2-by-2 design. One treatment is the Violence Recall versus Neutral Recall, as in the first experiment. The other treatment is a negative wealth shock (NWS). The NWS treatment was a reduction of $50 \%$ over the initial endowment (i.e., participants received an initial endowment of 10 points). Randomization occurs at the individual level. In Table 6 below, we summarize the design, with participants per condition.

Table 6. Experimental conditions and sample: Experiment 2

\begin{tabular}{ccc}
\hline & Violence Recall & Neutral Recall \\
\hline \multirow{2}{*}{ NWS } & VR \& NWS & NWS \\
& $\mathrm{N}=51$ & $\mathrm{~N}=60$ \\
No NWS & $\mathrm{VR}$ & Control \\
& $\mathrm{N}=51$ & $\mathrm{~N}=61$ \\
\hline
\end{tabular}


Julio 2019

\subsection{Procedures}

Experimental sessions were conducted at the Universidad Nacional de Colombia in Bogotá, from September 2018 to November 2018. A session had, on average, between six and 20 participants. The experiment was conducted using O-Tree (Chen, Schonger \& Wickens, 2016). All sessions started at 4:00 p.m. and lasted approximately one hour. The average payment was COP 14.000 (USD 5.00).

Participants arrived at the laboratory and were assigned a workstation (a picture of one of the sessions is in the SOM Photo A2). The assistant read the general instructions aloud and the participants signed the informed consent and completed the first questionnaire. Then, the assistant explained the PD task. After the explanation, the participants answered four comprehension questions. Wrong answers received feedback. Before the PD choice, the software randomly assigned one of the four experimental conditions to each participant. For the recall, participants had five minutes in which to answer.

After the assignment of the experimental condition, the participants made 19 district contingent decisions in the PD task. Instructions could be recalled at any time, by pressing a button. Then, participants had to go through the belief elicitation task. Then, they made the third decision; the donation in the dictator game with NGOs as receivers. There was no feedback of the PD results.

After performing all the decisions, the computer calculated the payoff. Anonymity was guaranteed at every moment. While envelopes were prepared, participants filled out the second block of the questionnaire. Finally, the participants received payment within the envelope, separately and privately.

An English version of all the materials and instructions are included in the SOM (including the screenshots from the program).

In total, we had 17 sessions, with 223 participants. The participants received on average COP 14,000 (with COP 6,779 sd). The sessions lasted one hour with very little variation. 


\subsection{Identification Strategy}

We run the following estimation:

$Y_{i, j}=\alpha+\beta_{V R} V R_{i, j}+\beta_{N W S} N W S_{i, j}+\beta_{V R \& N W S} V R \& N W S_{i, l}+\beta_{H E T V} H E T V_{i, j}+$

$\beta_{I N T \# V R} V R_{i, j} \cdot \operatorname{HETV}_{i, j}+\beta_{I N T \# N W S} N W S_{i, j} \cdot \operatorname{HETV}_{i, j}+\beta_{I N T \# V R \& N W S} V R \& N W S_{i, j} \cdot$

$\operatorname{HETV}_{i, j}+\gamma^{\prime} X_{i, j}+\delta^{\prime} Z_{j}+\varepsilon_{i, j}$

where $i$ indicates participant and $j$ the district. $Y$ is our dependent variable, VR is the dummy equal to one for the condition Violence Recall-No NWS, NWS is the dummy equal to one for the condition Neutral Recall-NWS, VR \& NWS is the dummy equal to one for the condition Violence Recall-NWS, HETV is the dummy equal to one for those highly exposed to violence, $X$ is a set of individual level controls, $Z$ is a set of district-level controls, and $\varepsilon$ are individual level unobservables.

Individual level controls are measured in the post-experimental questionnaire: we use SocioEconomic Strata, age, gender, the number of wrong answers in the comprehension questions, dummies for students and members of the Idipron program, ${ }^{8}$ educational level, and whether or not the participant was born in Bogotá.

We used a battery of district-level controls from the Bogotá Household Survey (Encuesta Multiproposito de Bogotá, EMB 2017). In particular, we used the following variables: average weekly expense, education, heterogeneity, mobility, and home ownership. These are the equivalent of the variables used in Falk and Zehnder (2013), adapted to Colombia, and are similar to the variables used in Experiment I. 'Average Weekly expense' corresponds to the sum of household expenditure on beverages and non-alcoholic foods, transportation, mail, fax and parcels, fuel and parking, meals outside the home, bets and lotteries and internet café. This is used instead of income per capita for data availability. 'Education' corresponds to the average number of years of schooling; 'Heterogeneity' is the percentage of SES 1 and 2 households in the district; 'Mobility' is the number of households in the district that moved to another location in the last 5 years; 'Home ownership' is the percentage of households that

\footnotetext{
${ }^{8}$ To include participants from two of the most dangerous districts, we recruited youngsters who belong to a special program which helps victims, the homeless and former drug addicts.
} 
Julio 2019

have their own home in the locality. We could not find the rate of internally displaced population, so we did not include it.

HETV is a dummy based on self-reported ETV. We recover these data from post experimental questionnaire. In particular, we used the following questions:

- In the last 12 months, have you been victim of
A. Non-armed robbery
B. Armed robbery
C. Assault or sexual violence
D. Kidnapping
E. Street fight
F. Domestic violence
G. Damage to your property, crops or animals
H. Extortion
I. Verbal aggression
J. Harassment
K. Persecution
L. Psychological abuse
M. Death threats?

From these data, using a principal components analysis, we retain the first component ${ }^{9}$ and we compute a composite self-reported violence index. The median level of ETV is again bounded away from zero, thus the coefficient can be interpreted as an intensive margin.

Our coefficients of interest are $\beta_{I N T \# V R}, \beta_{I N T \# N W S}$ and $\beta_{I N T \# V R \& N W S}$. In terms of Rubin's alternative potential outcomes model (Rubin, 1974), the interpretation of these coefficients is the difference in the impact of the administered treatment on the outcome variable between those with LETV and those with HETV. The identification assumptions are as follows: first, the observed effect of the treatment variable would be the same between LETV

\footnotetext{
${ }^{9} \mathrm{KMO}=0.63$, the eigenvalue of the first component is 2.49 , and the variance explained accounts for $19 \%$ of the total.
} 
and HETV, in absence of the increase in victimization, after controlling for observables; and second, the effect of the treatment can be interpreted causally because it is randomly assigned. We interpret Violence Recall as the inducement of the mental and emotional state related to the ETV. We interpret shock as recall of the NWS of victimization and of the related emotions (Delgado et al., 2006a; 2006b).

We estimate the impact of ETV on cooperation using the decisions in the PD. We calculate the average cooperation (i.e., the total of "blue" decisions over 19 possible decisions) across districts and we also look at separate decisions per district. We also estimate the impact of ETV on beliefs about cooperation. Finally, we estimate the share sent to NGOs, as a measure of altruism.

\subsection{Results: Impact on Pro-social Behavior}

In the SOM Table A13, we provide descriptive statistics of the sample by experimental condition.

In Figure 4 below, we report the results on cooperation. On the y-axis, we report the probability of cooperation, averaged out over the 19 district contingent decisions. To plot the results, we present three graphs with four groups: we first split by ETV (LETV versus HETV), and then we consider separately the control versus treatment in each subgroup. In this way, in the first graph we have the effect of recalling a fearful/anxious experience in LETV versus HETV, in the second graph the effect of an NWS in LETV versus HETV and in the third graph the combined effect of recall and NWS in LETV versus HETV. 
Julio 2019

Figure 4. The impact of Exposure to Violence on cooperation by experimental conditions: panel a) VR; panel b) NWS and; panel c) VR \& NWS
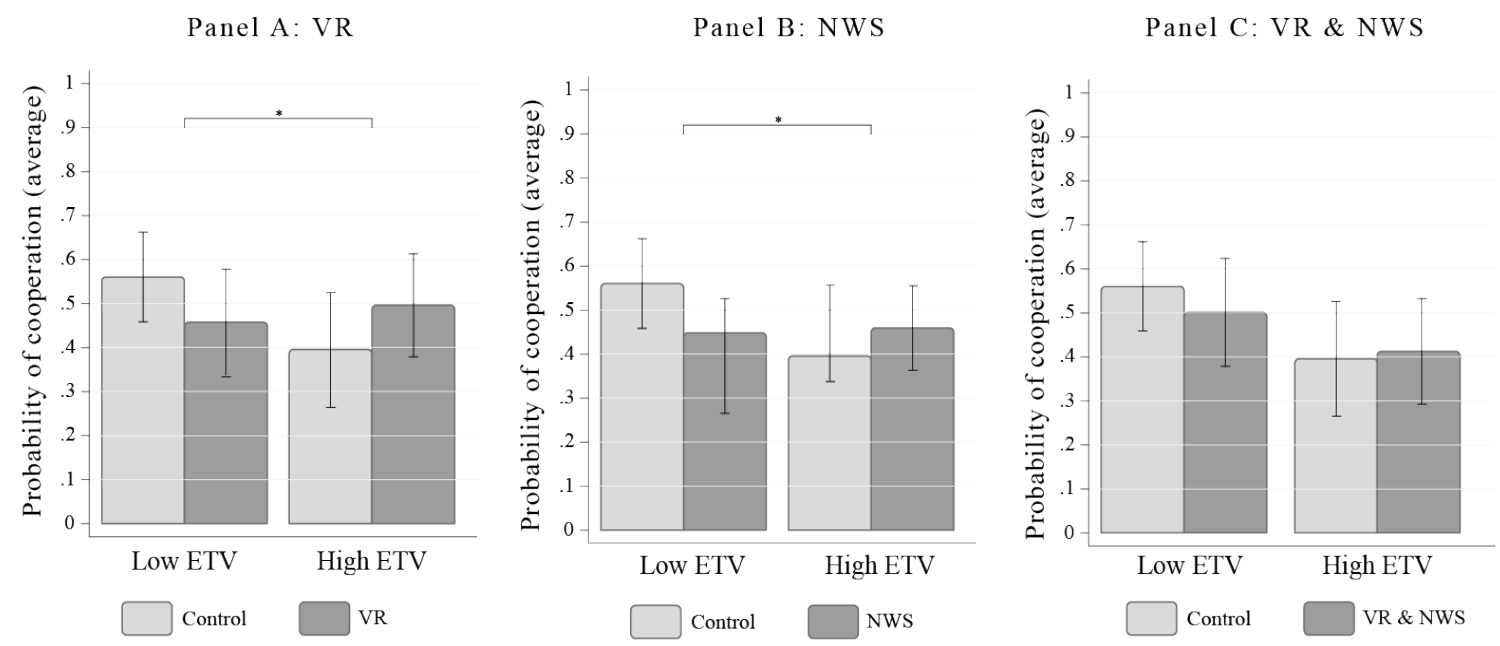

Source: Author's elaboration. The probability of cooperation is broken down by the four experimental conditions (Control, VR, NWS and VR \& NWS) and levels of ETV; high or low ETV. Panel A shows the impact of ETV in the VR condition, panel B shows the impact of ETV in the NWS condition and, panel C shows the impact of ETV in the VR \& NWS condition. High exposure to violence identifies subjects lying above the distribution's median split of the self-reported violence index. Error bars reflect $\pm 95 \%$ confidence intervals. Top horizontal bar shows the statistical significance of the difference in difference coefficient from the regression reported in Table 7. ${ }^{* * *} p<0.01,{ }^{* *} p<0.05,{ }^{*} p<0.1$.

For each of the groups, we then report the average cooperation, and the confidence interval at 95\%. Above the graph, we report the significant difference estimate from the dif-in-dif model in Equation [2].

We could replicate the result from Experiment 1. In fact, the recall of violence has a positive effect on cooperation in HETV with respect to LETV. In Table 8, we report all meaningful comparisons, to make sense of these results.

Again, it can be seen that for LETV, the recall has a negative impact, whereas recall in HETV has a positive effect. The double difference is $23 \%(t=1.95 ; p=0.052)$, which is significant.

Something similar happens for the negative wealth shock. Whereas for the LETV, NWS reduces the level of cooperation, for HETV, the NWS condition increases cooperation by $7 \%$. The double difference is $21 \%(t=1.92 ; p=0.056)$, which is significant. 
When we combine VR and NWS, we could not find a significant effect. However, the sign is the expected one. There may be an issue of power. Although the test is correctly sized, its power is $40 \%$. We calculate power ex post using a Monte Carlo approach based on Moffatt (2015). The supporting regression is reported in Table 7 below.

Table 7. Difference-in-difference estimation of the impact of self-reported ETV on cooperation

\begin{tabular}{|c|c|c|c|c|}
\hline \multirow[b]{2}{*}{ VARIABLES } & (1) & (2) & (3) & (4) \\
\hline & \multicolumn{4}{|c|}{ Probability of cooperation (average) } \\
\hline \multirow[t]{2}{*}{ VR } & -0.10 & -0.13 & -0.10 & -0.13 \\
\hline & $(0.08)$ & $(0.08)$ & $(0.08)$ & $(0.08)$ \\
\hline \multirow[t]{2}{*}{ NWS } & -0.11 & $-0.13^{*}$ & -0.11 & $-0.13^{*}$ \\
\hline & $(0.07)$ & $(0.07)$ & $(0.07)$ & $(0.07)$ \\
\hline \multirow[t]{2}{*}{ VR \& NWS } & -0.06 & -0.09 & -0.05 & -0.08 \\
\hline & $(0.08)$ & $(0.08)$ & $(0.08)$ & $(0.08)$ \\
\hline \multirow[t]{2}{*}{ HETV } & $-0.16^{* * *}$ & $-0.21^{* * *}$ & $-0.16^{*}$ & $-0.20 * *$ \\
\hline & $(0.08)$ & $(0.08)$ & $(0.08)$ & $(0.08)$ \\
\hline \multirow[t]{2}{*}{ VR \# HETV } & $0.20 *$ & $0.25 * *$ & 0.19 & $0.24 *$ \\
\hline & $(0.11)$ & $(0.12)$ & $(0.12)$ & $(0.12)$ \\
\hline \multirow[t]{2}{*}{ NWS \# HETV } & 0.18 & $0.22 * *$ & 0.16 & $0.21 *$ \\
\hline & $(0.11)$ & $(0.11)$ & $(0.11)$ & $(0.11)$ \\
\hline \multirow[t]{2}{*}{ VR \& NWS \# HETV } & 0.08 & 0.11 & 0.06 & 0.10 \\
\hline & $(0.12)$ & $(0.12)$ & $(0.12)$ & $(0.12)$ \\
\hline Individual controls & NO & YES & NO & YES \\
\hline District controls & NO & NO & YES & YES \\
\hline \multirow[t]{2}{*}{ Constant } & $0.56^{* * * *}$ & $0.49^{* * *}$ & 0.40 & 0.25 \\
\hline & $(0.05)$ & $(0.19)$ & $(0.45)$ & $(0.51)$ \\
\hline Observations & 223 & 223 & 223 & 223 \\
\hline R-squared & 0.03 & 0.07 & 0.03 & 0.08 \\
\hline F test & 0.910 & 0.903 & 0.596 & 0.771 \\
\hline
\end{tabular}

Note: The dependent variable 'Probability of cooperation' is the average of 19 cooperative decisions to the districts by participants. This variable is constrained to vary from 0 to 1 , where 1 is choose the cooperative strategy (blue). 'VR' identifies participants who were asked to recall emotions of anxiety and fear connected to an experience of urban violence. 'NWS' identifies participants who were exposed to a negative wealth shock (a reduction of $50 \%$ in the initial endowment). 'VR \& NWS' is the treatment of having both the recall of urban violence and the negative wealth shock. HETV is the dummy of exposure to urban violence where it is equal to 1 if the participant was classified to the group of high exposure to urban violence and is equal to 0 otherwise. Individual level controls include: Gender, Age, Education, SES, whether the participant is a member of the Idipron Foundation, the number of errors in the comprehension questionnaire, whether the participant is a student of the Universidad Nacional de Colombia, and whether the participant was born in Bogotá. District level controls were calculated from the micro data of the Multipurpose Survey of Bogotá, 2017: 'Average Weekly expense' corresponds to the sum of household expenditure on beverages and non-alcoholic foods, transportation, mail, fax and parcels, fuel and parking, meals outside the home, bets and 
Julio 2019

lotteries and internet cafe; 'Education' corresponds to the average number of years of schooling; 'Heterogeneity' is the percentage of SES 1 and 2 households; 'Mobility' is the number of households in that locality that moved to another location in the last 5 years; 'Home ownership' is the percentage of households that have their own home in the locality. Robust standard errors in parentheses. *** $p$ $<0.01, * * p<0.05, * p<0.1$ (See the complete regression in Table A 14 in SOM).

When we run a separate regression for our measure of altruism, we cannot find any effect, confirming the result from Experiment I. The regression is reported in SOM, Table A15.

Table 8. Comparing the four groups defined by ETV and Recall for Experiment II

\begin{tabular}{|c|c|}
\hline Variable & $\begin{array}{c}\text { Average } \\
\text { cooperation }\end{array}$ \\
\hline$y_{i}^{\text {LETV,Only Recall }}-y_{i}^{\text {LETV,Control }}$ & $\begin{array}{l}-0.13 \\
(0.08)\end{array}$ \\
\hline$y_{i}^{L E T V, \text { Only Shock }}-y_{i}^{L E T V, \text { Control }}$ & $\begin{array}{l}-0.13^{*} \\
(0.07)\end{array}$ \\
\hline$y_{i}^{L E T V, \text { Recall and Schok }}-y_{i}^{\text {LETV,Control }}$ & $\begin{array}{l}-0.07 \\
(0.08)\end{array}$ \\
\hline$y_{i}^{H E T V, \text { Control }}-y_{i}^{L E T V, \text { Control }}$ & $\begin{array}{l}-0.20^{* * *} \\
(0.08)\end{array}$ \\
\hline$y_{i}^{H E T V, \text { Only Recall }}-y_{i}^{H E T V, \text { Control }}$ & $\begin{array}{l}0.10 \\
(0.08)\end{array}$ \\
\hline$y_{i}^{H E T V, \text { Only Shock }}-y_{i}^{H E T V, \text { Control }}$ & $\begin{array}{c}0.07 \\
(0.08)\end{array}$ \\
\hline$y_{i}^{H E T V, \text { Recall and Shock }}-y_{i}^{H E T V, \text { Control }}$ & $\begin{array}{c}0.01 \\
(0.08)\end{array}$ \\
\hline $\begin{array}{l}{\left[\left(y_{i}^{\text {HETV,Only Recall }}-y_{i}^{L E T V, \text { Only Recall }}\right)\right.} \\
\left.-\left(y_{i}^{H E T V, \text { Control }}-y_{i}^{L E T V, \text { Control }}\right)\right]\end{array}$ & $\begin{array}{l}0.23 * \\
(0.12)\end{array}$ \\
\hline 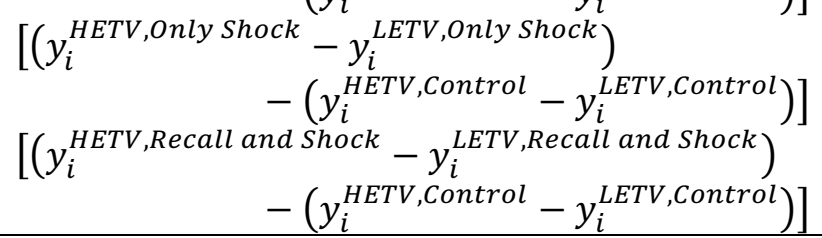 & $\begin{array}{c}0.21^{*} \\
(0.11) \\
0.09 \\
(0.12)\end{array}$ \\
\hline
\end{tabular}

Note: The table reports results from econometric analysis to explain average cooperation, see Table 7 above. The model estimated is the model of the Equation [2]. Robust standard errors (clustered at the session level for regression in the last column) are reported in parentheses. $* * * 0<0.01, * * p<0.05, *$ $\mathrm{p}<0.1$.

Among the other relevant comparisons, reported in Table 8 above, we can signal that going from LETV to HETV reduces average cooperation by $20 \%$, and the pure effect of shock in LETV is negative and significant. 


\subsection{Results: In-group Bias}

In Figure 5, we plot the results for in-group bias. We use the 19 decisions at the district level to estimate a panel data model. We introduce a dummy for those decisions that involve cooperation towards a resident in the same district.

We add three interactions with HETV and with VR, NWS, and VR \& NWS conditions to detect if there is a differential impact of ETV on in-group bias.

Figure 5. In-group bias at district level: cooperation

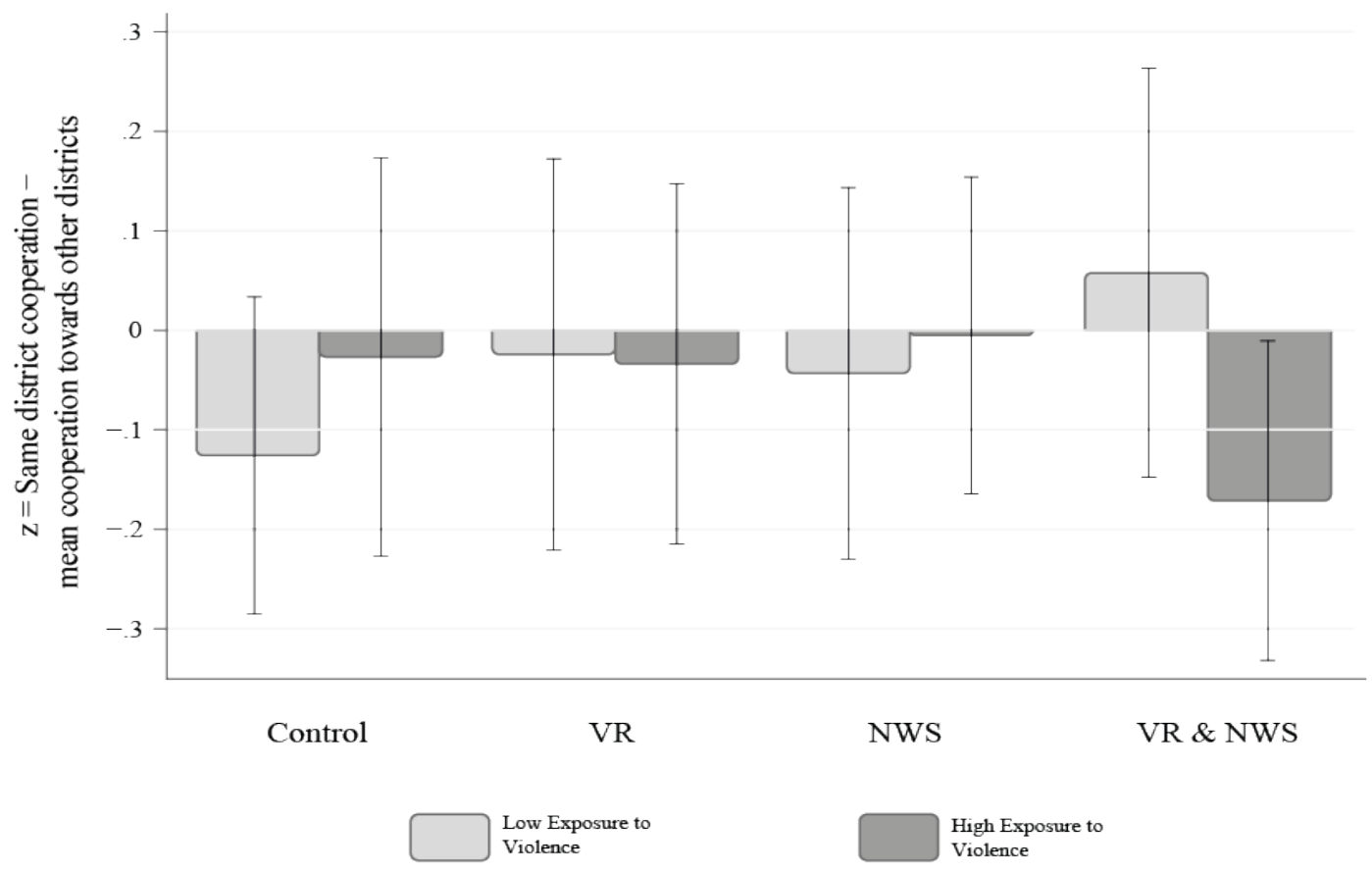

Source: Author's elaboration. The in-group variable $(z)$ is the difference between the cooperation towards the same district and the average cooperation toward the other 18 districts. This variable is broken down by the four experimental conditions (Control, VR, NWS and, VR \& NWS) and levels of ETV; high or low ETV. High exposure to violence identifies subjects lying above the distribution's median split of the self-reported violence index. Error bars reflect $\pm 95 \%$ confidence intervals. *** $\mathrm{p}<0.01, * * \mathrm{p}<0.05, * \mathrm{p}<0.1$.

As can be seen, there is no evidence of in-group bias and there are no differential impacts of ETV across the different experimental conditions. We report the estimation for in group in Table 9 below. 
Julio 2019

Table 9. In-group bias for cooperation

\begin{tabular}{|c|c|}
\hline VARIABLES & $\begin{array}{c}\text { (4) } \\
\text { Cooperation }\end{array}$ \\
\hline In-group & $\begin{array}{l}-0.12 \\
(0.08)\end{array}$ \\
\hline VR & $\begin{array}{l}-0.02 \\
(0.06)\end{array}$ \\
\hline NWS & $\begin{array}{l}-0.04 \\
(0.06)\end{array}$ \\
\hline VR \& NWS & $\begin{array}{l}-0.04 \\
(0.06)\end{array}$ \\
\hline HETV & $\begin{array}{l}-0.07 \\
(0.04)\end{array}$ \\
\hline In-group \# VR & $\begin{array}{c}0.09 \\
(0.12)\end{array}$ \\
\hline In-group \# NWS & $\begin{array}{c}0.07 \\
(0.12)\end{array}$ \\
\hline In-group \# VR \& NWS & $\begin{array}{c}0.18 \\
(0.12)\end{array}$ \\
\hline In-group \# HETV & $\begin{array}{c}0.09 \\
(0.12)\end{array}$ \\
\hline In-group \# VR \# HETV & $\begin{array}{l}-0.08 \\
(0.18)\end{array}$ \\
\hline In-group \# NWS \# HETV & $\begin{array}{l}-0.04 \\
(0.17)\end{array}$ \\
\hline In-group \# VR \& NWS \# HETV & $\begin{array}{l}-0.32^{*} \\
(0.17)\end{array}$ \\
\hline Individual controls & YES \\
\hline District controls & YES \\
\hline Constant & $\begin{array}{c}0.07 \\
(0.49)\end{array}$ \\
\hline Observaciones & 4,237 \\
\hline Número de ID & 223 \\
\hline Efectos aleatorios & sí \\
\hline
\end{tabular}

Note: 'In-group' is a dummy variable that takes the value of 1 if the district of destination is the same of the district of residence. 'VR' identifies participants who were asked to recall emotions of anxiety and fear connected to an experience of urban violence. 'NWS' identifies participants who were exposed to a negative wealth shock (a reduction of $50 \%$ in the initial endowment). 'VR \& NWS' is the treatment of having both the recall of urban violence and the negative wealth shock. HETV is the dummy of exposure to urban violence where it is equal to 1 if the participant was classified to the group of high exposure to urban violence and is equal to 0 otherwise. Robust standard errors in parentheses. ${ }^{* * *} \mathrm{p}<0.01,{ }^{* *} \mathrm{p}<0.05,{ }^{*} \mathrm{p}<0.1$. (See the complete regression in Table A 16 in SOM). 
It is worth mentioning that there are differences across districts in terms of cooperation. In other words, participants are not simply using the same strategy across districts. In fact, when we decompose the variance, we find that almost two thirds (66\%) of it is within participants, while the rest (34\%) is between participants.

\section{Mechanisms}

In the second part of our analysis, we investigate potential mechanisms. We start with the first experiment.

We first look at mediating variables identified by the existing literature. We recall that four variables have been highlighted: beliefs, social norms, psychological recovery, and the perception of insecurity.

We have the following measures of beliefs: first, the expected average transfer by the sender; second, the expected return (1T); and third, the expected return (2T). We use these variables as proxies for the neoclassical explanations.

To investigate evolutionary explanations of social norms, we follow two different avenues. We calculate the money spent as punishment as a share of the maximum possible. We have four punishment decisions. The first two are: the decision whether to punish or not the sharing by the recipient in the case of one transferred token and in the case of two transferred tokens, which represent anti-social punishments. We label them Antisocial punishment (1T) and Antisocial punishment (2T). The last two are: the decision whether to punish or not the keeping by the recipient in the case of one transferred token and in the case of two transferred tokens, which represents altruistic punishments. We label them Altruistic

punishment (1T) and Altruistic punishment (2T). Punishment is interpreted as the key mechanism to enforce social norms (Fehr and Fischbacher, 2004b).

To further analyze social norms as a theoretical mechanism, we estimate a model with a triple difference to see if there is a differential impact of TPP on those recalling and exposed to violence, with respect to those only recalling or only exposed to violence. 
Julio 2019

We explore the psychological recovery mechanism through a measure collected in the postexperimental questionnaire, asking in what SES they would expect to live throughout her/his life. This measure is not incentivized.

Finally, we explore the perception of insecurity using two questions from the postexperimental questionnaire, as in Vélez et al. (2016), adapted to the urban environment. These questions are:

- How likely do you think it will be for you to be a victim of violent assault in the next 12 months?

- Do you agree with the statement "The neighborhood where I live is violent"?

Again, we build an index based on the first component of the principal component analysis. ${ }^{10}$

We now present the evidence on mechanisms, as postulated by the existing literature. Results are reported in Figure 6 and in

Table 10 below.

${ }^{10} \mathrm{KMO}=0.50$, the eigenvalue of the first component is 1.13, and the variance explained $56 \%$. 
Figure 6. The causal mechanisms: Evidence from Experiment I

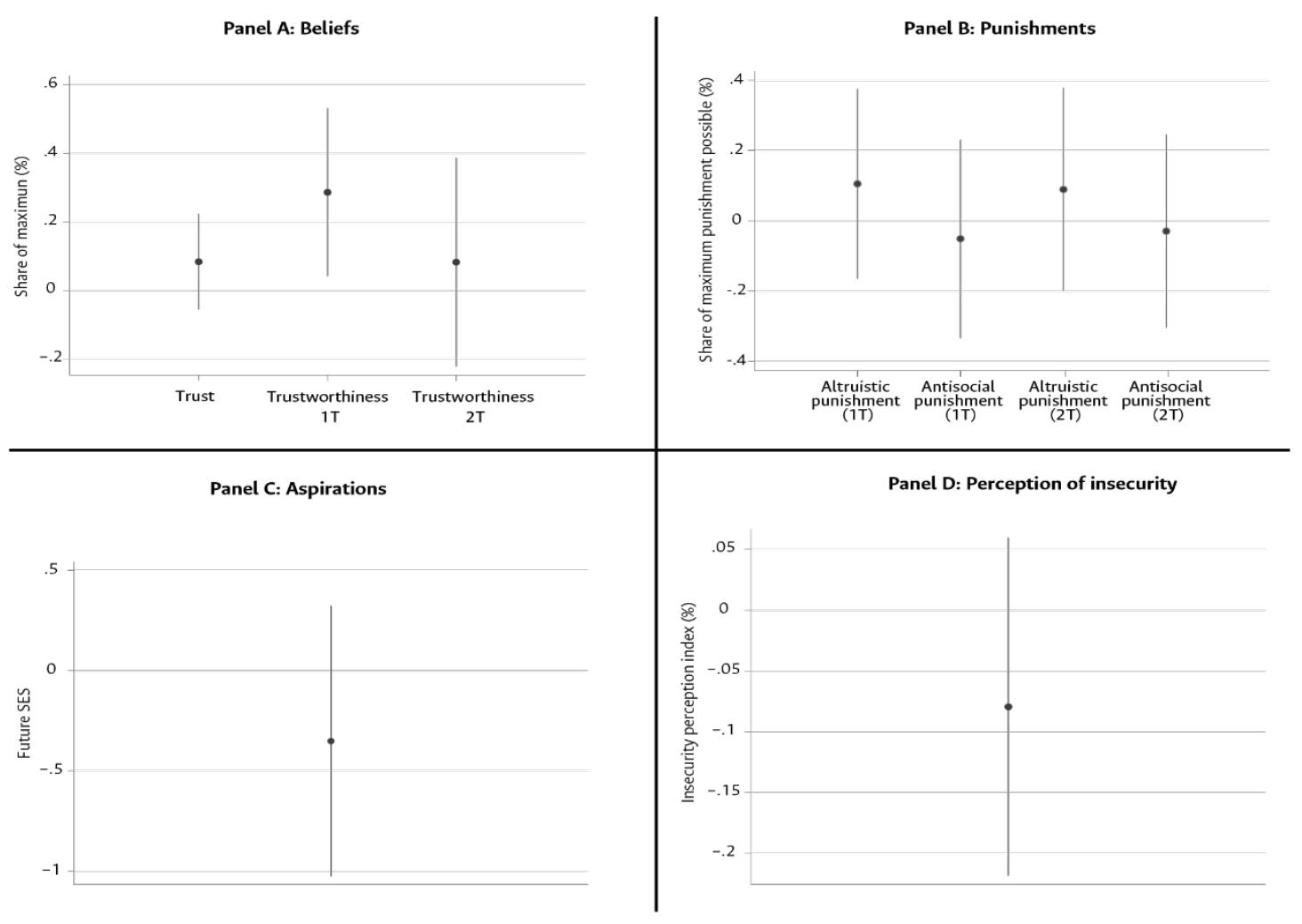

Source: Author's elaboration. The figure reports results from econometric analysis to explain the causal mechanisms. In all the panels we report the difference-in-difference estimator. Error bars reflect $\pm 95 \%$ confidence intervals. Panel A shows the differential effect on trust, trustworthiness (1T) and trustworthiness (2T) beliefs of ETV in both groups; Violence Recall (VR) and Neutral Recall (NR). Panel B shows the differential effect on altruistic punishment (1T), antisocial punishment (1T), altruistic punishment (2T) and antisocial punishment (2T) of ETV in both groups; Violence Recall (VR) and Neutral Recall (NR). Panel $C$ shows the differential effect on aspirations (expected future SES) of ETV in both groups; Violence Recall (VR) and Neutral Recall (NR). Panel D shows the differential effect on violence perception (insecurity perception index) of ETV in both groups; Violence Recall (VR) and Neutral Recall (NR). The regressions are reported in SOM Table A12. 
Julio 2019

Table 10. Triple difference estimation with triple interaction TPP-HETV-VR on z-score

\begin{tabular}{|c|c|c|c|c|}
\hline VARIABLES & $\begin{array}{c}(1) \\
\text { Prosocial }\end{array}$ & $\begin{array}{c}(2) \\
\text { Prosocial } \\
\end{array}$ & $\begin{array}{c}(3) \\
\text { Prosocial }\end{array}$ & $\begin{array}{c}(4) \\
\text { Prosocial } \\
\end{array}$ \\
\hline TPP & $\begin{array}{l}-0.02 \\
(0.15)\end{array}$ & $\begin{array}{l}-0.07 \\
(0.14)\end{array}$ & $\begin{array}{c}0.03 \\
(0.14)\end{array}$ & $\begin{array}{l}-0.01 \\
(0.14)\end{array}$ \\
\hline Violence recall & $\begin{array}{l}-0.26 \\
(0.22)\end{array}$ & $\begin{array}{l}-0.31 \\
(0.26)\end{array}$ & $\begin{array}{l}-0.31 \\
(0.24)\end{array}$ & $\begin{array}{l}-0.30 \\
(0.28)\end{array}$ \\
\hline HETV & $\begin{array}{l}-0.26 \\
(0.16)\end{array}$ & $\begin{array}{l}-0.27 \\
(0.16)\end{array}$ & $\begin{array}{l}-0.26 \\
(0.17)\end{array}$ & $\begin{array}{l}-0.26 \\
(0.17)\end{array}$ \\
\hline HETV \# VR & $\begin{array}{c}0.34 \\
(0.27)\end{array}$ & $\begin{array}{c}0.47 \\
(0.33)\end{array}$ & $\begin{array}{c}0.34 \\
(0.29)\end{array}$ & $\begin{array}{c}0.39 \\
(0.35)\end{array}$ \\
\hline HETV \# TPP & $\begin{array}{l}-0.07 \\
(0.22)\end{array}$ & $\begin{array}{l}-0.00 \\
(0.22)\end{array}$ & $\begin{array}{l}-0.06 \\
(0.22)\end{array}$ & $\begin{array}{l}-0.03 \\
(0.23)\end{array}$ \\
\hline TPP \# VR & $\begin{array}{c}0.07 \\
(0.28)\end{array}$ & $\begin{array}{c}0.03 \\
(0.32)\end{array}$ & $\begin{array}{c}0.11 \\
(0.29)\end{array}$ & $\begin{array}{l}-0.01 \\
(0.33)\end{array}$ \\
\hline HETV \# VR \# TPP & $\begin{array}{c}0.12 \\
(0.35)\end{array}$ & $\begin{array}{c}0.08 \\
(0.40)\end{array}$ & $\begin{array}{c}0.13 \\
(0.36)\end{array}$ & $\begin{array}{c}0.20 \\
(0.41)\end{array}$ \\
\hline Individual controls & NO & YES & NO & YES \\
\hline District controls & NO & NO & YES & YES \\
\hline Constant & $\begin{array}{c}0.17 \\
(0.10)\end{array}$ & $\begin{array}{l}-1.18^{*} \\
(0.66)\end{array}$ & $\begin{array}{l}-2.15^{*} \\
(1.16)\end{array}$ & $\begin{array}{c}-4.54^{* * * *} \\
(1.48)\end{array}$ \\
\hline Observations & 831 & 735 & 831 & 735 \\
\hline R-squared & 0.02 & 0.04 & 0.03 & 0.06 \\
\hline $\mathrm{F}$ test & 1.375 & 2.363 & 1.585 & 2.938 \\
\hline
\end{tabular}

Note: The dependent variable 'Pro-social' is the normalization in z-score of the trust, trustworthiness (1T), trustworthiness (2T), and altruism measures. This variable is centered in zero and in point of standard deviation. 'TPP' identifies participants who were assigned to the Third-Party Punishment treatment. 'Violence Recall' identifies participants who were asked to recall emotions of anxiety and fear connected to an experience of violence. HETV is a dummy for high exposure to violence, built from the post experimental questionnaire. Individual controls are age, female, father's education, and body mass index. District controls are district education, displacement rate, heterogeneity, mobility, and home ownership. Clustered standard errors at individual level in parentheses. ${ }^{* * *} \mathrm{p}<0.01, * *$ $\mathrm{p}<0.05,{ }^{*} \mathrm{p}<0.1$. (See the complete regression in Table A 5 in SOM).

In Figure 6, we plot the estimated coefficient for the interaction term in Equation [1], together with the confidence interval. In Panel A, we report separate estimations for the impact on the three measures of beliefs. In Panel B, we report the estimation for the impact on the two measures of anti-social and two measures of pro-social punishment. In Panel C, 
we report the estimate for the impact on aspirations. Finally, in Panel D, we report the estimated impact on the perception of insecurity.

There is weak evidence that the belief on trust $(0.14, t=2.13, p=0.035)$ and the beliefs on trustworthiness $(1 \mathrm{~T})(0.41, \mathrm{t}=2.89, \mathrm{p}=0.004)$ are differentially higher in those exposed to violence and recall, with respect to those who do not recall. There is no evidence on other mechanisms.

When we explore the evolutionary explanation in terms of the differential impact of the TPP in those exposed to violence who recall, with respect to those who don't recall or have low exposure to violence, we could not find any significant difference. The results are presented in

\section{Table 10.}

We then conducted a similar analysis for the second experiment.

We use the elicited belief of cooperation as a proxy for the neoclassical explanation.

To investigate evolutionary explanations of social norms, we use political participation. Some theorists interpret voting as the direct product of a social norm (Gerber and Rogers, 2009).

Again, we explore the psychological recovery mechanism through a measure collected in the post-experimental questionnaire, asking in what SES they would expect to live throughout her/his life. This measure is not incentivized.

Finally, we explore the perception of insecurity using eight questions from the postexperimental questionnaire, as in Vélez et al. (2016), adapted to the urban environment. These statements are:

- I feel safe when going out at night 
Julio 2019

- I feel I could face threats to my life

- I fear for my life

- I feel I face risks when participating in social, economic and political meetings

- I fear being robbed by day

- I fear being robbed by night

- I fear personal aggression by day

- I fear personal aggression by night.

Again, we build an index based on the first component of the principal component analysis. ${ }^{11}$

We now present the evidence on mechanisms. Results are reported in Figure 7 below.

Figure 7. The causal mechanisms: Evidence from Experiment II

${ }^{11} \mathrm{KMO}=0.74$, the eigenvalue of the first component is 3.42 , and the variance explained amounts to $42 \%$. 


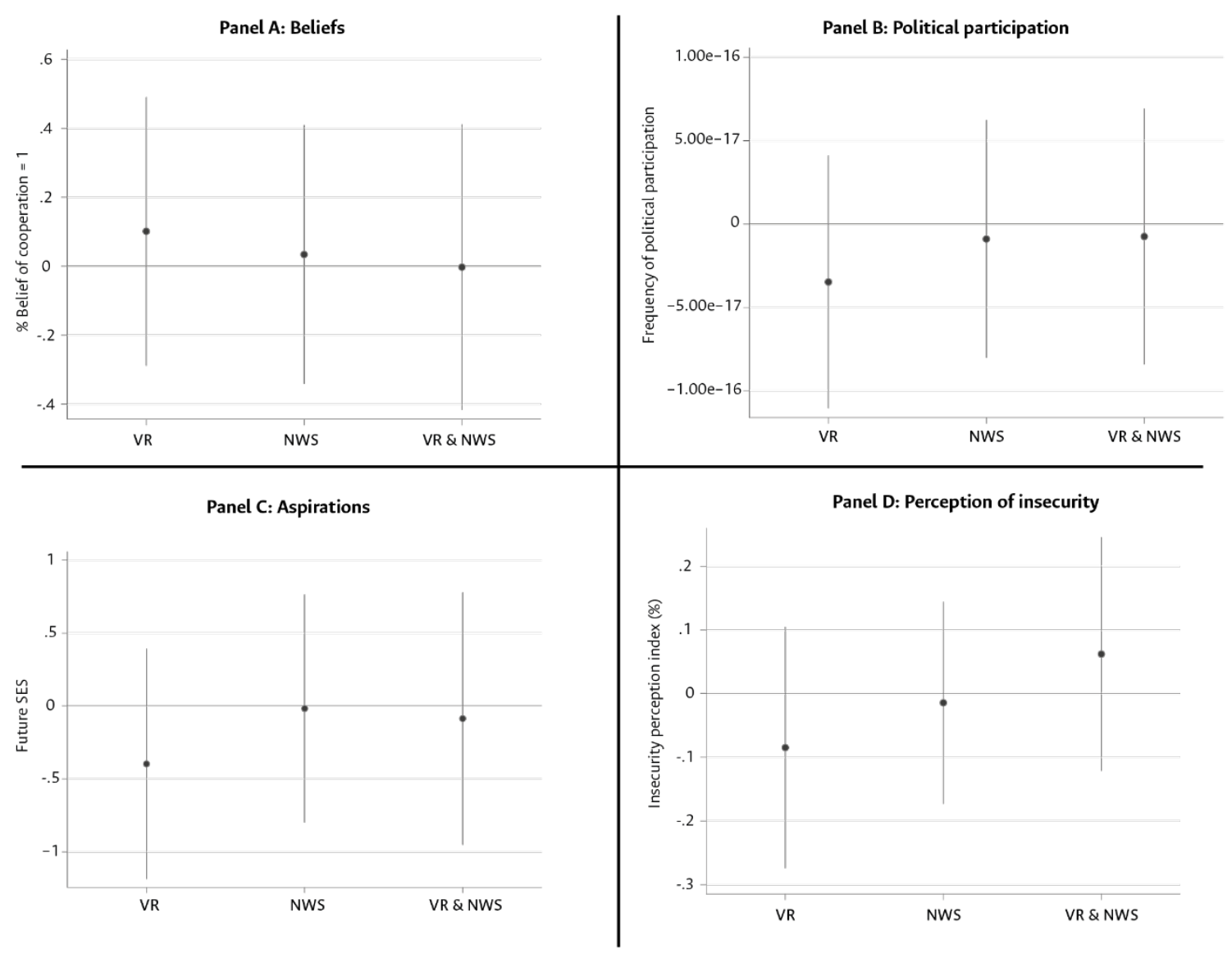

Source: Author's elaboration. The figure reports results from econometric analysis to explain the causal mechanisms. In all the panels we report the difference-in-difference estimator. Error bars report $\pm 95 \%$ confidence intervals. Panel A shows the differential effect on belief of cooperation of ETV in the three experimental conditions (VR, NWS and, VR \& NWS). Panel B shows the differential effect on political participation of ETV in the three experimental conditions (VR, NWS and, VR \& NWS). Panel $C$ shows the differential effect on aspirations (expected future SES) of ETV in the three experimental conditions (VR, NWS and, VR \& NWS). Panel D shows the differential effect on perception of insecurity of ETV in the three experimental conditions (VR, NWS and, VR \& NWS). The regressions are reported in SOM Table A17.

In Figure 7, we plot the estimated coefficient for the interaction term in Equation [2], together with the confidence interval. In Panel A, we report separate estimations for the impact on the measure of belief. In Panel B, we report the estimation for the impact on political participation. In Panel C, we report the estimate for the impact on aspirations. Finally, in Panel $D$, we report the estimated impact on the perception of insecurity. There is no evidence of any of these mechanisms. In other words, we could find no compelling evidence that these are the causal channels. In our opinion, there is a generalized explanation, based on two possible arguments. 
Julio 2019

Bogliacino et al. (2017) show that ETV-related trauma reduces cognitive control and memory. Their results are consistent with both dual-process theory (Sloman, 1996; Kahneman, 2011) according to which ETV (and its recall) triggers a reaction that makes the reflexive system dominant, with the stress-induced release of catecholamine that hampers the functioning of the pre-frontal cortex (Bogliacino et al., 2017; Roth et al., 1988).

Additionally, Bogliacino and Montealegre (2019) perform a laboratory experiment where people suffering wealth and income shocks perform worse in a cognitive index built with a Raven test, a short-term memory task and a cognitive version of the Real Effort task, and use time less efficiently (results are significant for both wealth alone and wealth plus income shock).

Can ETV affect cooperation through a change in cognitive functioning? This is known in the literature as the Social Heuristics Hypothesis (Rand et al., 2012; Bear and Rand, 2015). The hypothesis is predicated upon the intuitive nature of cooperation in humans. In their original experiment, Rand et al. (2012) manipulate the time available in a Public Good Game. They find that participants in the time pressure condition contribute significantly more to the public good, while those instructed to reflect contribute significantly less than baseline. This hypothesis suggests that social norms, experience or other baseline preferences carry over to the experimental settings, as shown by the absence of effect in experienced player as respect to naïve players (Rand et al., 2012; Rand et al., 2014), or by the heterogeneity of the effect after conditioning on baseline preferences (Krajbich et al., 2015; Alós-Ferrer and Garagnani, 2018).

Our results are consistent with this explanation because no participants had previous experience with an experimental laboratory. Additionally, it is interesting to note that in the debate over the Social Heuristics Hypothesis, meta-reviews suggest that those manipulations based on emotions are the most effective (Kvarven et al., 2019, Rand, 2019), and both the recall and the shock induce emotions (Bogliacino et al., 2017; Delgado et al., 2006).

The role of emotions in explaining the results is consistent with an alternative perspective. Declerc and Boone (2015) propose an explanation of pro-social behavior that relies on the 
existence of two heuristics that can be activated at the moment of taking a cooperative/trusting decision. This theory is an alternative to the dual system because both heuristics are partly deliberative and partly automatic. According to the authors, the two heuristics can be stated as, "I am selfish unless there are cooperative incentives", and "I am cooperative unless my partner is untrustworthy". Economically rational heuristic predicts cooperative behavior when there are incentives to do so, and socially rational heuristic reacts to social cues, such as a sense of belonging and a fear of ostracism, inducing cooperative behavior. For evolutionary reasons, we are wired to both mechanisms, which coexist in the brain and respond to alternative circuits. Extrinsic incentives activate cognitive control while trust signals activate social cognition. They both are associated with the mesolimbic reward system that projects the expected reward from an action motivating in favor of or against cooperation.

We know from extensive research on animals and humans that the processing of emotions (and fear in particular) involves the activity of the amygdala (Ledoux, 2003; Delgado et al., 2006), a region of the brain involved in social cognition (Adolphs, 2010). In this model, the social cognition activates trust or threat signals to mitigate or arouse the fear of being betrayed, inducing or impairing pro-social conduct. ${ }^{12}$ It is possible that under adverse emotional shocks, participants are particularly attentive to the detection of trustworthy signals from the safe laboratory environment, leading to increased cooperation.

\section{Concluding Remarks}

In this paper, we explore to what extent victims of violence in an urban context are more prosocial, using experimental measures of trust and cooperation.

In our theoretical framework, ETV is associated with trauma and negative economic shocks. We conducted two controlled experiments in Bogotá (Colombia). In both cases, we measured

\footnotetext{
12 This is also consistent with the evidence from PTSD. In these studies, they show abnormal regulation of catecholamine, in particular excess production of norepinephrine, which are shown to perform a similar function of serotonin in promoting pro-social behavior (Tse and Bond, 2002a, 2002b, 2003, 2006).
} 
Julio 2019

ETV and manipulated trauma, through a violence recall, and the exposure to a negative economic shock, through endowment losses.

Although we run artefactual field experiments where participants come from an urban environment, we replicate the results of the field studies performed with victims of conflict, which show deep other-regarding concerns. The result on the in-group bias is not robust to the choice of the task.

In the second part of this work, we discuss potential mechanisms. According to our data, there is no treatment effect of either trauma or negative shocks in victim over beliefs, social norms, psychological recovery, or the perception of insecurity. Building on our previous work, we conjecture that the cognitive load associated with both trauma and negative shock can explain more cooperation according to the Social Heuristics Hypothesis, or that the emotional shocks associated with our treatment may activate social cognition, inducing more cooperation. As is always the case, more research is necessary, but this is the first study that credibly proposes a unified explanation for the relationship between ETV and pro-social behavior.

\section{References}

Adolphs, R. (2010) What does the amygdala contribute to social cognition? ANNALS OF THE NEW YORK ACADEMY OF SCIENCES, 1191: 42-61

Alós-Ferrer, C, Garagnani, M (2018) The Cognitive Foundations of Cooperation, Working paper

Bateson, R. (2012). Crime Victimization and Political Participation. American Political Science Review, 106(3), 570-587. https://doi.org/10.1017/S0003055412000299

Bauer, M., Blattman, C., Chytilová, J., Henrich, J., Miguel, E., \& Mitts, T. (2016). Can War Foster Cooperation? Journal of Economic Perspectives, 30(3), 249-274. https://doi.org/10.1257/jep.30.3.249 
Bear, A, Rand, D (2015) Intuition, deliberation, and the evolution of cooperation, PNAS, 6 | doi:10.1073/pnas.1517780113

Bejarano, H, Gillet, J, Rodriguez-Lara, I (2018) Do Negative Random Shocks Affect Trust and Trustwortiness? Southern Economic Journal, 85(2): 563-579

Berg, J., Dickhaut, J., and McCabe, K. (1995). Trust Reciprocity and Social History. Games and Economic Behavior, 10.

Bignon, V., Caroli, E., \& Galbiati, R. (2017). Stealing to Survive? Crime and Income Shocks in Nineteenth Century France. The Economic Journal, 127(599), 19-49. https://doi.org/10.1111/ecoj.12270

Blanco, M, D. Engelmann, A. Koch \& H. Normann (2010) Belief Elicitation in Experiments: Is There a Hedging Problem?, Experimental Economics, 13(4), 412-438.

Bogliacino, F., Grimalda, G., Ortoleva, P., \& Ring, P. (2017). Exposure to and recall of violence reduce short-term memory and cognitive control. Proceedings of the National Academy of Sciences. https://doi.org/10.1073/pnas.1704651114

Bogliacino, F., Jiménez Lozano, L., \& Grimalda, G. (2018). Consultative democracy and trust. Structural Change and Economic Dynamics, 44, 55-67. https://doi.org/10.1016/j.strueco.2017.10.004

Bogliacino, F., Jiménez Lozano, L., \& Reyes, D. (2018). Socioeconomic stratification and stereotyping: lab-in-the-field evidence from Colombia. International Review of Economics, 65(1), 77-118. https://doi.org/10.1007/s12232-017-0285-4

Bogliacino, F, Montealegre, AF (2019) The effect of Negative Economic Shocks on Cognitive Functioning, Cheating and Loss Aversion: Evidence from the Lab, mimeo

Boscarino, J. A. (2006). Posttraumatic stress disorder and mortality among U.S. Army veterans 30 years after military service. Annals of Epidemiology, 16(4), 248-256. https://doi.org/10.1016/j.annepidem.2005.03.009 
Julio 2019

Bowles, S., \& Polanía-Reyes, S. (2012). Economic Incentives and Social Preferences: Substitutes or Complements? Journal of Economic Literature, 50(2), 368-425. https://doi.org/10.1257/jel.50.2.368

Callen, M., Isaqzadeh, M., Long, J. D., \& Sprenger, C. (2014). Violence and risk preference: Experimental evidence from Afghanistan. American Economic Review. https://doi.org/10.1257/aer.104.1.123

Charness, G., Du, N., \& Yang, C. L. (2011). Trust and trustworthiness reputations in an investment game. Games and Economic Behavior, 72(2), 361-375. https://doi.org/10.1016/j.geb.2010.09.002

Chen, D. L., Schonger, M., \& Wickens, C. (2016). oTree-An open-source platform for laboratory, online, and field experiments. Journal of Behavioral and Experimental Finance, 9, 88-97. https://doi.org/10.1016/j.jbef.2015.12.001

Cohen, R (1984) Warfare and State Formation: Wars Make States and States Make Wars in: Ferguson, BR (Ed) Warfare, Culture, and Environment. Orlando, FL: Academic Press, 329-358

Coleman, J. S. (1988). Social Capital in the Creation of Human Capital Social Capital in the Creation of Human Capital. American Journal of Sociology, 94, 95-120. Retrieved from http://www.jstor.org/stable/2780243

Cortés, D., Santamaría, J., \& Vargas, J. F. (2016). Economic shocks and crime: Evidence from the crash of Ponzi schemes. Journal of Economic Behavior and Organization, 131, 263-275. https://doi.org/10.1016/j.jebo.2016.07.024

Declerk, C, Boone, C (2015) Neuroeconomics of Prosocial Behavior, Elsevier.

Delgado, MR, Labouliere, CD, Phelps, EA (2006a) Fear of losing money? Aversive conditioning with secondary reinforcers, SCAN, 1: 250-259

Delgado, MR, Olsson, A, Phelps, EA (2006b) Extending animals models of fear conditioning to 
humans. Biological Psychology, 73: 39-48

Dorff, C. (2017). Violence, kinship networks, and political resilience: Evidence from Mexico. Journal of Peace Research, 54(4), 558-573. https://doi.org/10.1177/0022343317691329

Dube, O., \& Vargas, J. (2013). Commodity Price Shocks and Civil Conflict: Evidence from. Review of Economic Studies, (February), 1384-1421

Eckel, C. C., \& Grossman, P. J. (1996). Altruism in anonymous dictator games. Games and Economic Behavior. https://doi.org/10.1006/game.1996.0081

Falk, A., \& Zehnder, C. (2013). A city-wide experiment on trust discrimination. Journal of Public Economics, 100, 15-27. https://doi.org/10.1016/j.jpubeco.2013.01.005

Fehr, E and Fischbacher, U (2004a) Social norms and human cooperation. TRENDS in Cognitive Science, 8(4): 185-190

Fehr, E and Fischbacher, U (2004b) Third Party Punishment and Social Norms. Evolution and Human Behavior, 25, 63-87

Fehr, E. (2009). On the economics and biology of trust. Journal of the European Economic Association, 7(2-3), 235-266. https://doi.org/10.1162/JEEA.2009.7.2-3.235

Frieze, IH, Hymer, S., Greenberg, MS (1987) Describing the Crime Victim: Psychological Reactions to Victimization. Professional Psychology: Research and Practice 18(4): 299315

Gerber, AS, Rogers, T (2009) Descriptive Social Norms and Motivation to Vote: Everybody's Voting and so Should You. The Journal of Politics, 71(1): 178-191

Guiso, L., Sapienza, P., \& Zingales, L. (2006). Does Culture Affect Economic Outcomes? Journal of Economic Perspectives, 20(2), 23-48. https://doi.org/10.1257/jep.20.2.23 
Julio 2019

de Heus, P., Hoogervorst, N., \& Dijk, E. van. (2010). Framing prisoners and chickens: Valence effects in the prisoner's dilemma and the chicken game. Journal of Experimental Social Psychology. https://doi.org/10.1016/j.jesp.2010.04.013

Hardin, R. (1997). One for all: The logic of group conflict. Princeton University Press.

Harrison, GW and JA List (2004) Field Experiments. Journal of Economic Literature,Vol.42, No. 4, pp. 1009-1055

Haushofer, J, Fehr, E (2014) On the psychology of poverty. Science, 344, 862-867

Holt, C. A., \& Capra, M. (2000). Classroom games: A prisoner's dilemma. Journal of Economic Education. https://doi.org/10.1080/00220480009596781

Ibáñez, A. M., \& Moya, A. (2010). Vulnerability of Victims of Civil Conflicts: Empirical Evidence for the Displaced Population in Colombia. World Development, 38(4), 647-663. https://doi.org/10.1016/j.worlddev.2009.11.015

Kahneman, D (2011) Thinking, Fast and Slow. Penguin Books

Katz, CM, Webb, VJ, Fox, K, Shaffer, JN (2011) Understanding the relationship between violent victimization and gang membership, Journal of Criminal Justice, 39: 48-59

Kessler, R. C., Sonnega, A., Bromet, E., Hughes, M., \& Nelson, C. B. (1995). Posttraumatic Stress Disorder in the National Comorbidity Survey. National Comorbidity Survey, 5(1), 48-60. https://doi.org/10.1001/archpsyc. 1995.03950240066012

Kelly RC (2005) The evolution of lethal intergroup violence. Proc Natl Acad Sci USA 102:15294-15298.

Kochel, T. R. (2016). Police legitimacy and resident cooperation in crime hotspots: effects of victimisation risk and collective efficacy. Policing and Society, 28(3), 251-270. https://doi.org/10.1080/10439463.2016.1174235

Knack, S. and Keefer, P. (1997). Does Social Capital Have an Economic Payoff? A CrossCountry Investigation. The Quarterly Journal of Economics, 112(4):1251-1288. 
Krajbich, I., Bartling, B., Hare, T., and Fehr, E. (2015). Rethinking Fast and Slow Based on a Critique of Reaction-time Reverse Inference. Nature Communications, 6:7455

Kvarven, A., Strømland, E., Wollbrant, C. E., Andersson, D., Johannesson, M., Tinghög, G., Myrseth, K. R. (2019, April 16). The Intuitive Cooperation Hypothesis Revisited: A Metaanalytic Examination of Effect-size and Between-study Heterogeneity. https://doi.org/10.31222/osf.io/kvzg3

La Porta, R., \& et al. (1999). The Quality of Government. Journal of Law, Economics, and Organization, 15(1), 222-279. https://doi.org/http://jleo.oxfordjournals.org

LeDoux, J (2003) The Emotional Brain, Fear, and the Amygdala. Cellular and Molecular Neurobiology, 23(4/5): 727-738

Lerner, J. S., Gonzalez, R. M., Small, D. A., \& Fischhoff, B. (2003). Effects of fear and anger on perceived risks of terrorism: A national field experiment. Psychological Science, 14(2), 144-150. https://doi.org/10.1111/1467-9280.01433

Littman, R, Estrada, S, Stagnaro, MN, Dunham, Y, Rand, D, Baskin-Sommers, A (2019) Community Violence and Prosociality: Experiencing and Committing Violence Predicts Norm-Enforcing Punishment but Not Cooperation, Social Psychological and Personality Science, 1-8

McMahon, SD, Todd, NR, Martinez, A, Coker, C, Sheu, C-F, Washburn, J, Shah, S (2013) Aggressive and Prosocial Behavior: Community Violence, Cognitive, and Behavioral Predictors Among Urban African American Youth. Am J Community Psychol (2013) $51: 407-421$

Moffatt, P (2015) Experimetrics: Econometrics for Experimental Economics. Palgrave Moya, A. (2018). Violence, psychological trauma, and risk attitudes: Evidence from victims of violence in Colombia. Journal of Development Economics, 131, 15-27. https://doi.org/10.1016/j.jdeveco.2017.11.001

Moya, A, Carter, MR (2019) Violence and the formation of hopelessness: Evidence from internally displaced persons in Colombia. World Development, 113: 100-115 
Julio 2019

Pieschacón Fonrodona, M (2011) Trastorno de Estrés Postraumático. Bogotá: Universidad de Los Andes

Putnam, R. D., Leonardi, R., \& Nanetti, R. (1993). Making democracy work. Civic traditions in modern Italy.

Rand, DG (2019) Intuition, Deliberation, and Cooperation Further Meta-Analytic Evidence from 91 Experiments on Pure Cooperation. mimeo

Rand, D. G., Peysakhovich, A., Kraft-Todd, G. T., Newman, G. E., Wurzbacher, O., Nowak, M. A., \& Green, J. D. (2014). Social heuristics shape intuitive cooperation. Nature Communications, 5, Article 3677. doi:10.1038/ncomms4677

Rand, DG, Greene, JD, Nowak, MA (2012) Spontaneous giving and calculated greed, Nature, 489: $437-430$

Rojo-Mendoza, R. (2014). From Victims to Activists: Crime Victimization, Social Support and Political Participation in Mexico. Unpublished Paper.

Roman, C. G. (2008). Fear of walking outdoors: a multilevel ecological analysis of crime and disorder. American Journal of Preventive Medicine, 34, 306e312.

Romano, J. P. and Wolf, M. (2005). Stepwise multiple testing as formalized data snooping. Econometrica, 73(4):1237-1282

Rubin, D. B. (1974). Estimating causal effects of treatments in randomized and nonrandomized studies. Journal of Educational Psychology, 66(5), 688-701. https://doi.org/10.1037/h0037350

Scheidel, W. (2017) The Great Leveler. Princeton: Princeton University Press

Selten, R. (1967). Die Strategiemethode zur Erforschung des eingeschränkt rationalen Verhaltens im Rahmen eines Oligopolexperiments. In Beiträge zur experimentellen Wirtschaftsforschung (pp. 136-168).

Sloman SA (1996) The empirical casefortwo systems of reasoning. Psychological Bulletin 
$119: 3-22$

Sumner, W. G. (1906). Folkways: A Study of the Sociological Importance of Usages. Manners, Customs, Mores, And Morals (Boston, MA: Gin and Company, 1906), 12

Takagi, D, Ikeda, K, Kawachi, I (2012) Neighborhood social capital and crime victimization: Comparison of spatial regression analysis and hierarchical regression analysis. Social Science \& Medicine, 75: 1895-1902

Tse, WS, Bond, AJ (2002a) Difference in serotonergic and noradrenergic regulation of human social behaviours. Psychopharmacology, 159: 216-221

Tse, WS, Bond, AJ (2002b) Serotonergic intervention affects both social dominance and affiliative behaviour. Psychopharmacology 161: 324-330

Tse, WS, Bond, AJ (2003) Reboxetine promotes social bonding in healthy volunteersJournal of Psychopharmacology 17(2):189-195

Tse, WS, Bond, AJ (2006) Noradrenaline Might Enhance Assertive Human Social Behaviours: An Investigation in a Flatmate Relationship. Pharmacopsychiatry, 39: 175-179

Vélez MA, Trujillo CA, Moros L, Forero C (2016) Prosocial Behavior and Subjective Insecurity in Violent Contexts: Field Experiments. PLoS ONE 11(7): e0158878. https://doi.org/10.1371/journal.pone.0158878

Yehuda, R., \& Schuster, M. A. (2002). Post-traumatic stress disorder. New England Journal of Medicine, 346(2), 108-114. https://doi.org/10.1056/NEJMra012941/n346/2/108 [pii]

Zak, P. J., Knack, S. (2001). Trust and Growth. Economic Journal, 111(470), 295-321. https://doi.org/http://dx.doi.org/10.2139/ssrn.136961 